\title{
Exploring the Role of Cluster Formation in UiO Family Hf Metal- Organic Frameworks with in Situ X-ray Pair Distribution Function Analysis
}

Francesca C. N. Firth, Michael W. Gaultois, Yue Wu, Joshua M. Stratford, Dean S. Keeble, Clare P. Grey, and Matthew J. Cliffe*

Cite This: https://doi.org/10.1021/jacs.1c06990

Read Online

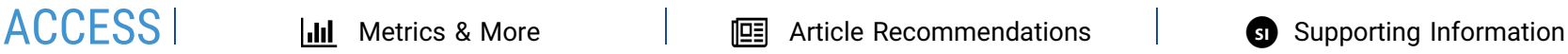

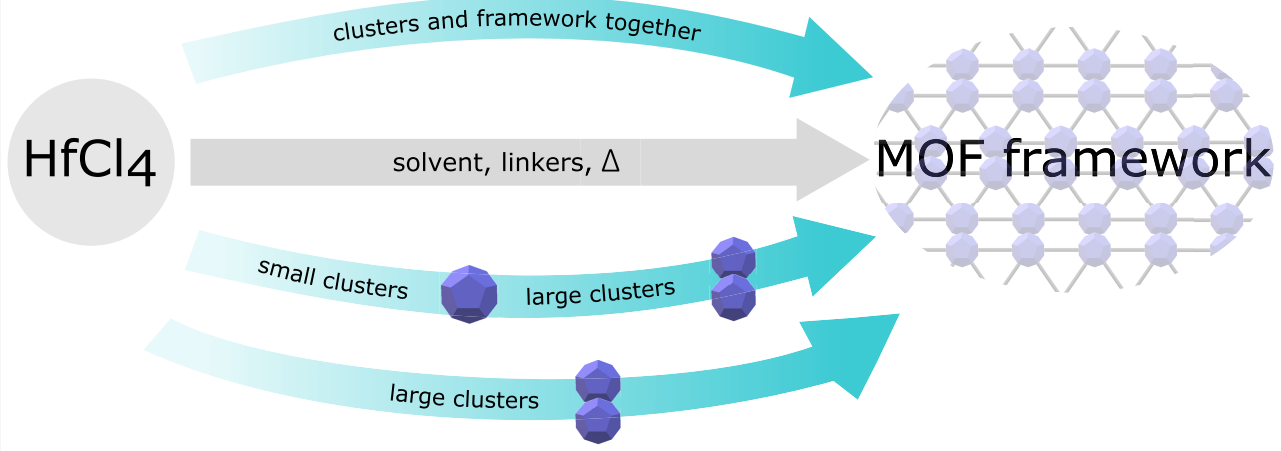

ABSTRACT: The structures of $\mathrm{Zr}$ and Hf metal-organic frameworks (MOFs) are very sensitive to small changes in synthetic conditions. One key difference affecting the structure of UiO MOF phases is the shape and nuclearity of $\mathrm{Zr}$ or $\mathrm{Hf}$ metal clusters acting as nodes in the framework; although these clusters are crucial, their evolution during MOF synthesis is not fully understood. In this paper, we explore the nature of Hf metal clusters that form in different reaction solutions, including in a mixture of DMF, formic acid, and water. We show that the choice of solvent and reaction temperature in UiO MOF syntheses determines the cluster identity and hence the MOF structure. Using in situ X-ray pair distribution function measurements, we demonstrate that the evolution of different $\mathrm{Hf}$ cluster species can be tracked during UiO MOF synthesis, from solution stages to the full crystalline framework, and use our understanding to propose a formation mechanism for the hcp UiO-66(Hf) MOF, in which first the metal clusters aggregate from the $\mathrm{M}_{6}$ cluster (as in fcu UiO-66) to the hcp-characteristic $\mathrm{M}_{12}$ double cluster and, following this, the crystalline hcp framework forms. These insights pave the way toward rationally designing syntheses of as-yet unknown MOF structures, via tuning the synthesis conditions to select different cluster species.

\section{INTRODUCTION}

Metal-organic frameworks (MOFs) are of great interest for a wide variety of applications, including energy storage and carbon capture, ${ }^{1,2}$ and have outstanding chemical tunability. ${ }^{3}$ In order to fully exploit the potential of MOFs for real-world applications, however, we must work toward designing syntheses to obtain MOFs with new sorption or catalytic properties, particularly enabled by new or previously inaccessible structures. While to some extent this can be achieved by the use of new geometries and functionalities of organic linker, one of the key components determining the structure of a MOF is the shape and identity of the metal cluster. ${ }^{4}$ The metal clusters are often modeled as "secondary building units", which direct the framework topology; therefore, by increasing our understanding of the inorganic component, we can obtain control over the nuclearity of the cluster and hence the connectivity of the MOF, which allows us to dramatically change the MOF structure.

Zirconium and hafnium are particularly favorable for the design of new MOF structures: in contrast to copper, for example (which often forms dinuclear "paddlewheel" units ${ }^{6}$ ), there is a rich variety of known zirconium and hafnium clusters, with a wide range of nuclearities, geometries, and coordination denticities. $^{7-11}$ There are in fact over 1300 structures containing between 3 and $21 \mathrm{Zr}$ or $\mathrm{Hf}$ ions in their molecular formula-forming either molecular clusters or being

Received: July 8, 2021 
part of an extended framework (including MOFs) - in the CCDC (Cambridge Crystallographic Database) alone (Cambridge Crystallographic Database, search performed July 2020). ${ }^{12}$

From these structures, we can identify a wide variety of $\mathrm{Zr}$ and $\mathrm{Hf}$ metal-oxide inorganic substructures (derived by removing peripheral ligands) or "core" clusters. The metal ions have a high charge density, arising from their +4 oxidation state, and so favor hard donor atoms such as oxygen, to which they coordinate strongly. Therefore, hydroxyl bridges and oxoand hydroxo-capped clusters are predominant in the $\mathrm{Zr}$ and $\mathrm{Hf}$ core clusters, and clusters are often found with ligands coordinating through oxygen, such as carboxylate groups. ${ }^{13,14}$

Although the most common cluster motif in $\mathrm{Zr}$ and $\mathrm{Hf}$ MOFs, e.g., in the UiO family ${ }^{15}$ [Figure 1], is the $\mathrm{M}_{6}\left(\mu_{3^{-}}\right.$

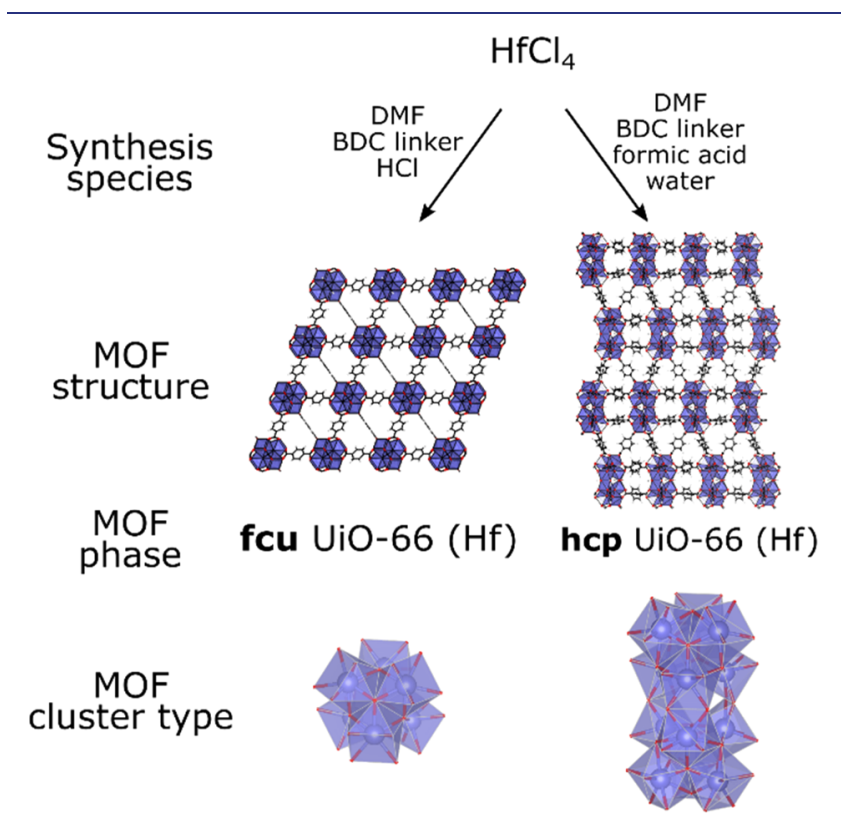

Figure 1. Differences in synthesis conditions of $\mathrm{UiO}$ family MOFs lead to the formation of different MOF phases. ${ }^{55} \mathrm{~A}$ synthesis performed with $\mathrm{HCl}$ leads to the fcu MOF structure with $\mathrm{Hf}_{6}\left(\mu_{3}\right.$ $\mathrm{O})_{4}\left(\mu_{3}-\mathrm{OH}\right)_{4}$ "single" clusters, while a synthesis performed with formic acid and water leads to the hcp MOF structure with $\left[\mathrm{Hf}_{6}\left(\mu_{3^{-}}\right.\right.$ $\left.\mathrm{O})_{4}\left(\mu_{3}-\mathrm{OH}\right)_{4}\right]_{2}\left(\mu_{2}-\mathrm{OH}\right)_{6}$ "double" clusters: the type and nuclearity of the metal cluster affect the topology via the change in linker coordination site number and geometry. The metal-oxide coordination polyhedra are also shown. Color scheme: $\mathrm{Hf}$ or $\mathrm{Zr}$, blue; $\mathrm{O}$, red; C, black; H, white.

$\mathrm{O})_{4}\left(\mu_{3}-\mathrm{OH}\right)_{4}$ cluster based on $\mathrm{Zr}_{6} \mathrm{O}_{8}$ octahedra, ${ }^{9,16,17}$ the core clusters range from small, low-nuclearity molecular clusters through to large structures such as infinite polymeric chains. ${ }^{18-22}$ Just as in other extended metal oxide structures, these metal (hydr)oxide clusters can share vertices, ${ }^{9}$ edges, ${ }^{17,23}$ faces, and coordination-polyhedra. ${ }^{9,24-26}$ As these structures increase in nuclearity, they increasingly resemble the structure of high temperature, tetragonal $\mathrm{ZrO}_{2} .{ }^{2.7}$

The standard method for synthesizing $\mathrm{Zr} / \mathrm{Hf}$ MOFs is solvothermal synthesis; the choice of solvent affects the MOF metal clusters, with the degree of $\mathrm{Zr}$ or Hf cluster aggregation being greatly affected in particular by the presence of water in the synthesis. In aqueous, and especially aqueous acidic conditions, the distorted-square tetrameric species $\left[\mathrm{M}_{4}(\mathrm{OH})_{8} \cdot 16 \mathrm{H}_{2} \mathrm{O}\right]^{8+}$ is dominant. ${ }^{26,28-33}$ This cluster is surrounded by a structured coordination sphere of water molecules ${ }^{34,35}$ similar to other nanoparticles in solution. ${ }^{36}$ This water coordination sphere is potentially the source of further hydroxide bridges between metal centers during condensation of the clusters. ${ }^{34,35,37-39}$ The degree of hydrolysis, and subsequent aggregation, can be modulated by the use of additional reagents, ${ }^{38}$ such as acid, ${ }^{40}$ which in some MOF syntheses are required to form the crystalline framework ${ }^{41,42}$ and in others are used to control particle morphology. ${ }^{16,41,43,44}$ Monocarboxylic acids are often chosen for this purpose; since they can possess a wide range of metal-ligand binding strengths, a judicious choice of carboxylic acid can "block" coordination sites on the cluster to further nucleophilic attack preventing, in the case of water/hydroxides, cluster aggregation or, for linkers, the formation of multicluster framework species. ${ }^{14,35,45}$ However, while it is now clear that water and modulating ligands are critical to the identity and stability of the resultant metal clusters (from ligand-terminated molecular clusters $^{31}$ through to MOFs ${ }^{13,35,46-49}$ ), the exact interplay of these factors, especially in multispecies reaction mixtures, is not well-understood.

The degree of cluster aggregation is also directly affected by the temperature and duration of the synthesis. Both heating acidic aqueous zirconium solutions, for example, during a solvothermal synthesis, and aging the reaction mixture increase the amount of bridging $\mu_{2}-\mathrm{OH}$ between metal centers and also encourage their conversion to $\mu_{3}-\mathrm{O}$ and $\mu_{3}-\mathrm{OH}$ groups. ${ }^{16,31,35,50}$ This therefore favors the formation of higher-nuclearity $\mathrm{Zr}$ or Hf clusters. ${ }^{51}$

Building on this work, we recently showed that, by tuning the synthesis conditions of $\mathrm{UiO}$ family MOFs, ${ }^{15,52-54}$ we can produce MOFs with distinct and different framework topologies, caused by the formation of different nuclearities of different zirconium or hafnium metal clusters. ${ }^{17,55,56}$ Increasing the temperature, concentration of water, and concentration of formic acid modulator allowed us to selectively produce $\mathrm{UiO}$ family hafnium MOFs containing larger $\mathrm{Hf}_{12}$ metal clusters, namely hcp (hexagonal close-packed) UiO-66 (Hf) and hcp and hns (hexagonal nanosheets) $\mathrm{UiO}-67(\mathrm{Hf})$, instead of $\mathrm{Hf}_{6}$ clusters, which form the fcu (face-centered cubic) topology [Figure 1].

Our previous work showed that, due to the similarities between the powder X-ray diffraction (PXRD) patterns of the fcu and hcp MOFs, ${ }^{17,55}$ it is not always immediately obvious that a MOF structure with a different cluster has formed. Despite advances in understanding, ${ }^{57-61}$ including studies on the effects of different variables (including acid modulator, water, and organic linker) on the crystallization of $\mathrm{UiO}-66$ (zirconium $^{42,62}$ and cerium analogues ${ }^{63}$ ), the focus of much current research is on the crystallization process rather than the metal cluster formation, which directs the crystallization. A full picture of the formation routes of MOFs is therefore still far off. In our work on $\mathrm{UiO}$ family MOFs, in situ measurements to probe crystallization of the hcp phase suggested that inorganic (i.e., largely free from organic ligands) precrystalline species formed at early stages in the synthesis. ${ }^{17}$ Although this inorganic, noncrystalline material is likely to be a key intermediate in the formation and crystallization of $\mathrm{UiO}$ family MOFs, we were unable to determine its identity. Moreover, it is unknown when in the reaction the crucial structural differences between $\mathrm{UiO}$ MOF phases emerge (i.e., selectivity of the hcp phase over the fcu); it is unclear whether the different clusters form via different routes or if they pass 
through common intermediates. Finally, the timing of the cluster interlinking and framework growth, relative to the timing of the formation of the different clusters, has been little explored.

Studies on $\mathrm{Zr}$ and $\mathrm{Hf}$ clusters to track or solve their structures are not straightforward (especially in situ studies of solvothermal syntheses) because Bragg diffraction cannot be used to study these critical noncrystalline species. Solution NMR is extremely challenging, as the key nuclei $\left({ }^{17} \mathrm{O},{ }^{91} \mathrm{Zr}\right.$, ${ }^{177} \mathrm{Hf}$, and ${ }^{179} \mathrm{Hf}$, in the absence of organic linker species ${ }^{64,65}$ ) all either have large quadrupole moments (e.g., $Q\left({ }^{177} \mathrm{Hf}\right)=4.9$ b), ${ }^{66}$ have low gyromagnetic ratios (e.g., $\gamma\left({ }^{179} \mathrm{Hf}\right)=-0.682 \times$ $10^{7} \mathrm{rad} / \mathrm{Ts}$ ), or are of very low abundance (e.g., ${ }^{17} \mathrm{O}=$ $0.038 \%)$. While extended X-ray absorption fine structure (EXAFS) methods can identify $\mathrm{Zr}$ and $\mathrm{Hf}$ species in solution and are sensitive to species with low abundance, this technique is limited to smaller molecular clusters such as the tetramer and single cluster, ${ }^{31}$ due to multiple scattering events reducing the sensitivity to longer-range coordination, such as that seen in the molecular double cluster or in the interlinked MOF.

$\mathrm{X}$-ray pair distribution function (XPDF) measurements can acquire structural information on noncrystalline species and are particularly sensitive to heavier elements such as $\mathrm{Zr}$ and $\mathrm{Hf}$ due to their high electron density. When applied to MOFs, XPDF measurements can be used to understand the local structure of disordered and noncrystalline MOFs and their clusters and precursors ${ }^{67}$ and to investigate the interactions between clusters and coordinating molecules. ${ }^{68}$ In our previous work, we have demonstrated that ex situ XPDF measurements are sensitive to the identity of the cluster in UiO family MOFs and can clearly distinguish between isolated $\mathrm{Zr}$ atoms, $\mathrm{Zr}_{6}$ clusters, and $\mathrm{Zr}_{12}$ clusters. ${ }^{17}$ Ex situ XPDF measurements can detect and differentiate between tetramer and single cluster species in room temperature solutions related to $\mathrm{UiO}$ syntheses $^{57}$ and have successfully been used in situ to track the size of interlinked cluster aggregates forming MOF crystallites in solvothermal UiO-66 syntheses, ${ }^{57}$ as well as of metal oxido nanoclusters. ${ }^{69}$ However, until now, no study has been able to follow both the cluster formation-especially of higher-nuclearity clusters - and the coordination of the MOF framework in the same in situ reaction.

It is imperative to further explore the in situ formation of $\mathrm{Hf}$ and $\mathrm{Zr} \mathrm{MOFs}$ and their related clusters and precursors, in order to understand their behavior when combined with other species, with different identities and concentrations, which are present under solvothermal conditions. The future of MOF design lies in the rational synthesis of new desired MOF structures, with a range of connectivities and different linkers and subsequently different physical/chemical properties and topologies. The identification of relevant conditions that can be exploited to synthesize new MOF clusters can be used alongside techniques such as high-throughput synthesis to efficiently optimize the synthesis for novel MOFs, including nanomaterials. ${ }^{70,71}$ In order to do this, through the deliberate design of syntheses to exploit the wide library of possible cluster species, we must improve our understanding of the mechanisms of MOF and MOF-precursor formation. In this work, we bridge the gap between ex situ cluster identification and in situ MOF crystallite growth. We focus our investigation on the UiO-66 family of MOFs, as an archetype of $\mathrm{Zr} / \mathrm{Hf}$ MOFs. We perform in situ XPDF measurements on reactions of Hf-containing solutions, under conditions required to form both the hcp UiO-66(Hf) MOF and its molecular cluster precursors. We show that, alongside a careful structure search for plausible cluster models, these XPDF measurements enable us to identify critical cluster intermediates in the materials, including the $\mathrm{M}_{6}$ cluster found in fcu UiO-66(Hf) and the $\mathrm{M}_{12}$ double cluster found in hcp UiO-66(Hf). We also gain insight into the relationship between the cluster formation and the MOF framework coordination. These advances in understanding the stages of growth of $\mathrm{UiO}$ family MOFs, including the formation of clusters as precursors, provide routes toward the deliberate and efficient design of MOF syntheses, exploiting the wide library of possible metal cluster species for new and unrealized members of this important class of materials.

\section{EXPERIMENTAL METHODS}

No unexpected or unusually high safety hazards were encountered in the course of this work.

Synthesis. All reagents used were obtained from commercial suppliers and used without further purification.

Reaction mixtures were carried out in a $2.5 \mathrm{~mm}$ fused-quartz capillary, sealed with a Teflon cap before being loaded into the in situ cell.

An aqueous solution of $\mathrm{HfCl}_{4}$ (30 wt \%) was prepared through the dissolution of $\mathrm{HfCl}_{4}$ (Acros Organics, 99\%) in deionized water and sonication for $10 \mathrm{~min}$.

The conditions for the synthesis of the hcp UiO-66(Hf) MOF were adapted from ref 54 , with quantities reduced to account for the smaller in situ reaction volume. The concentrations of $\mathrm{HfCl}_{4}$ and, where relevant, organic linker were increased to improve signal-tonoise. The compositions of the reaction mixtures are described below.

$\mathrm{HfCl}_{4}(4.8 \mathrm{mg}, 0.015 \mathrm{mmol})$ and terephthalic acid $\left(\mathrm{H}_{2} \mathrm{BDC}\right)$ (Alfa Aesar, $98 \%, 2.5 \mathrm{mg}, 0.015 \mathrm{mmol}$ ) were added to a capillary, followed by the addition of dry $N, N$-dimethylformamide (Sigma-Aldrich, 99.85\% anhydrous DMF) (65 $\mu \mathrm{L}$ ), formic acid (Fisher, 98/100\%) $(25 \mu \mathrm{L})$, and water $(10 \mu \mathrm{L})$; then, the mixture was sonicated for 10 min. We also carried out reactions without the terephthalic acid ligand to assess its importance in cluster formation. $\mathrm{HfCl}_{4}(116 \mathrm{mg}, 0.362$ $\mathrm{mmol}$ ) was sonicated for $10 \mathrm{~min}$ with dry DMF $(6.5 \mathrm{~mL})$, formic acid $(2.5 \mathrm{~mL})$, and water $(1.0 \mathrm{~mL})$. The resulting solution $(0.1 \mathrm{~mL})$ was measured into the capillary.

In Situ Measurements. Total scattering X-ray diffraction patterns were collected at beamline I15-1 at the Diamond Light Source using an X-ray energy of $76.7 \mathrm{keV}(\lambda=0.161669 \AA)$. Initial calibration measurements were performed on a NIST silicon standard. In situ measurements were carried out using a heated steel sample holder with openings for the X-ray beam to pass through the sample. The capillary was positioned so that the beam passed through it close to the base, so that any solid formed during the reaction would not precipitate out of the path of the beam. Once the capillary was loaded, heating was started with a fast ramp; then, scattering detection and temperature measurements proceeded at a rate of one scan per minute. Two separate thermocouples measured the temperature of the capillary and of the sample holder. The experimental setup of the hydrothermal cell is depicted in Figure S1. Diffraction measurements of capillaries containing pure water and the 65:25:10 DMF/formic acid/water solvent were taken at room temperature and at $150{ }^{\circ} \mathrm{C}$ for use as backgrounds. In situ experiments were performed at room temperature and 120 and $150{ }^{\circ} \mathrm{C}$.

Analysis. The diffraction data were integrated using DAWN ${ }^{72}$ and processed, with corrections applied for background, meaningful instrument intensity cutoff, and polynomial smoothing using the PDFgetX3 software package ${ }^{73}$ using the following parameters: $q_{\min }=$ $1 \AA^{-1}, q_{\max }=22.5 \AA^{-1}$, and $r_{\text {poly }}=1.24 \AA$.

Structural models were quantitatively refined against XPDF data using the DiffPy-CMI software package. ${ }^{74}$ The resolution peak dampening term $Q_{\text {damp }}$ was constrained to $Q_{\text {damp }}=0.035 \AA^{-1}$; this value was derived from refinement against a NIST Si standard. The deltal parameter, corresponding to correlated-atomic-motion-derived 
peak broadening in the "high temperature limit" (with a $1 / r$ dependence), was set to $2 \AA$ following an initial refinement, and the isotropic displacement parameters $\left(U_{\text {iso }}\right)$ were derived from the reported values for $\mathrm{Hf}$ clusters, determined from single-crystal data, and set to $0.18 \AA^{2}$ for $\mathrm{H}, 0.075 \AA^{2}$ for $\mathrm{C}$, and $0.06 \AA^{2}$ for O. $U_{\text {iso }}$ for $\mathrm{Hf}$ was obtained from the refinement of an ex situ sample of hcp UiO66(Hf) [Figure S2] and subsequently fixed at $0.0069 \AA^{2}$. The refinement of isolated cluster models and the optimized full structure model of hcp UiO-66(Hf) was carried out with the refinement parameters set to $q_{\min }=1 \AA^{-1}, q_{\max }=22.5 \AA^{-1}, r_{\text {poly }}=1.24 \AA$, and $r_{\text {min }}$ $=1.5 \AA$ XPDF patterns of the cluster models were simulated using the DiffPy-CMI software package, ${ }^{74}$ with the optimized parameters as detailed above. Peak tracking and analysis of processed XPDF and powder X-ray diffraction (PXRD) data was performed using the NumPy and SciPy packages. ${ }^{75,76}$

This paper uses the PDFGui convention for the normalization of $F(Q)$ and $G(r) .^{77}$

\section{RESULTS}

In order to study the in situ formation of UiO-66 family MOFs, we designed a series of experiments based on the conditions used in our lab syntheses of these materials, as summarized in Table 1. While UiO family MOFs are typically synthesized

Table 1. Summary of Experimental Conditions Used in the XPDF Studies, Listing the Solvent, Nature of Linkers (if any), and Temperatures Used

\begin{tabular}{|c|c|c|c|}
\hline experiment & solvent & linker & temperature \\
\hline 1 & water & no & R.T. \\
\hline 2 & DFW 65:25:10 ${ }^{a}$ & no & R.T. \\
\hline 3 & DFW $65: 25: 10^{a}$ & no & $150^{\circ} \mathrm{C}$ \\
\hline 4 & DFW 65:25:10 ${ }^{a}$ & $\mathrm{BDC}$ & $150^{\circ} \mathrm{C}$ \\
\hline 5 & DFW 65:25:10 & no & $120^{\circ} \mathrm{C}$ \\
\hline 6 & DFW $65: 25: 10^{a}$ & $\mathrm{BDC}$ & $120^{\circ} \mathrm{C}$ \\
\hline
\end{tabular}

${ }^{a}$ The notation "DFW 65:25:10" gives the volume ratio of DMF/ formic acid/water.

from zirconium salts, in this (as with our previous) work, we used hafnium chloride, due to the chemical similarity of Hf to $\mathrm{Zr}$ but greater scattering power. ${ }^{55}$ While a variety of solvents and conditions have been used across the literature, the majority of our work has focused on reactions in DMF with formic acid and water. ${ }^{17,55}$ Our XPDF experiments, therefore, used these same reagents.

We initially observed the behavior of our $\mathrm{HfCl}_{4}$ metal salt in water alone as a baseline, since the behavior of $\mathrm{ZrCl}_{4}$ in water is well-established. We then focused on a 65:25:10 (by volume) $\mathrm{DMF} /$ formic acid/water mixture (referred to below as "DFW 65:25:10") as a solvent, setting out to elucidate the behavior of the UiO-related system throughout the reaction at different temperatures. We also investigated whether the stages and rate of cluster formation are affected by the presence of additional coordinating linkers and explored the timing of the framework growth and crystallinity relative to the cluster formation, by performing reactions at the two different temperatures both with and without terephthalic acid $\left(\mathrm{H}_{2} \mathrm{BDC}\right)$ linker, i.e., reactions with the potential to form $\mathrm{UiO}-66$-type structures (containing $\mathrm{BDC}$, at 150 and $120^{\circ} \mathrm{C}$ ) and molecular-cluster-only reactions (no BDC, at 150 and 120 $\left.{ }^{\circ} \mathrm{C}\right)$ [Table 1].

We start by detailing our approach to model the different clusters present, beginning with the aqueous solution of $\mathrm{HfCl}_{4}$. We then consider the effect of changing the solvent and temperature and the effect of adding linkers on the type and evolution of the clusters in these UiO-related systems.

Cluster Models. Since there are many possible cluster structures adopted by $\mathrm{Zr}$ and $\mathrm{Hf}$ in solution, we first identified all the relevant clusters that could be present in our system via a systematic search of the Cambridge Structural Database (CSD). This search yielded over 1300 structures containing 3-21 $\mathrm{Zr}$ or $\mathrm{Hf}$ atoms per structural unit, including both clusters in molecules and those in extended frameworks (including "infinite" structures with repeating subunits) [Figure 2a]. The majority of $n<3$ search results contained higher-nuclearity clusters, but with the molecular formula reduced to an empirical formula; very few clusters with $n>21$ were observed. We then discarded all structures containing heterometallic clusters and extracted the metal (hydr)oxo core clusters by stripping out the peripheral ligands, giving us more than 170 unique results. Our candidates were then reduced to 25 core clusters by considering only those feasible in typical MOF reaction conditions and within the constraints of our experimental conditions [Figure 2b]. We then discarded core clusters appearing only once, those with syntheses reported to be irreproducible, and those from syntheses requiring more than a few days (i.e., with reaction times more than 2 orders of magnitude longer than used in our experiments) or temperatures below $0{ }^{\circ} \mathrm{C}$ and further only considered clusters reported to form in reaction mixtures containing water. The remaining 25 clusters included the classic (fcu) $\mathrm{UiO}_{6}$ single cluster and hcp $\mathrm{UiO} \mathrm{M}_{12}$ double cluster [Figure 1]. Of note, one of these original 25 clusters, the HIKSIF $\mathrm{Zr}_{8}$ cluster, has subsequently been shown to be instead a $\mathrm{Zr}_{6}$ cluster, $^{78}$ consistent with the stability of this particular cluster type.

The initial examination of an in situ XPDF data set of a linker-free reaction in DFW 65:25:10 solvent [Figure 2c] revealed that low- $r$ peaks were only experimentally observed in six regions (as illustrated in Figure 3 ). For this linker-free reaction, no peaks above $r=11 \AA$ were observed. While intercluster interactions in our MOFs are expected to occur at distances greater than $11 \AA$, these reactions in solution are likely to be highly dynamic and so will not produce defined peaks in PDF data due to motional averaging, in contrast with interactions between interlinked clusters in a framework. Applying the constraint that the simulated XPDF of the core clusters should not have peaks outside the regions seen in the in situ data set narrowed down the 25 chemically feasible core clusters to five [Figure 3], removing those core clusters with peaks outside these regions. We edited all five core cluster models to obtain the $\mathrm{Hf}$ (rather than $\mathrm{Zr}$ ) analogues, in keeping with the composition of our reaction mixtures.

In order to obtain our cluster models, we removed peripheral ligands from the original structures. However, in our reactions, it is likely that the clusters are coordinated by a combination of carboxylate groups ${ }^{31}$ (formate and/or BDC, where present in the synthesis) and water/hydroxide ${ }^{55}$ (the tetramer is predominantly coordinated by water only). ${ }^{26,31} \mathrm{We}$ therefore added coordinating oxygen atoms to the five core cluster models to allow for the presence of nonspecific peripheral ligands while avoiding chemically unrealistic undercoordinated metal centers.

Hf Behavior in Water. Due to the similarity between the calculated XPDF patterns of the five core clusters, we turned to the quantitative refinement of the structures against the experimental data with Diffpy-CMI ${ }^{74}$ to determine the composition of our reaction mixtures. To validate our 

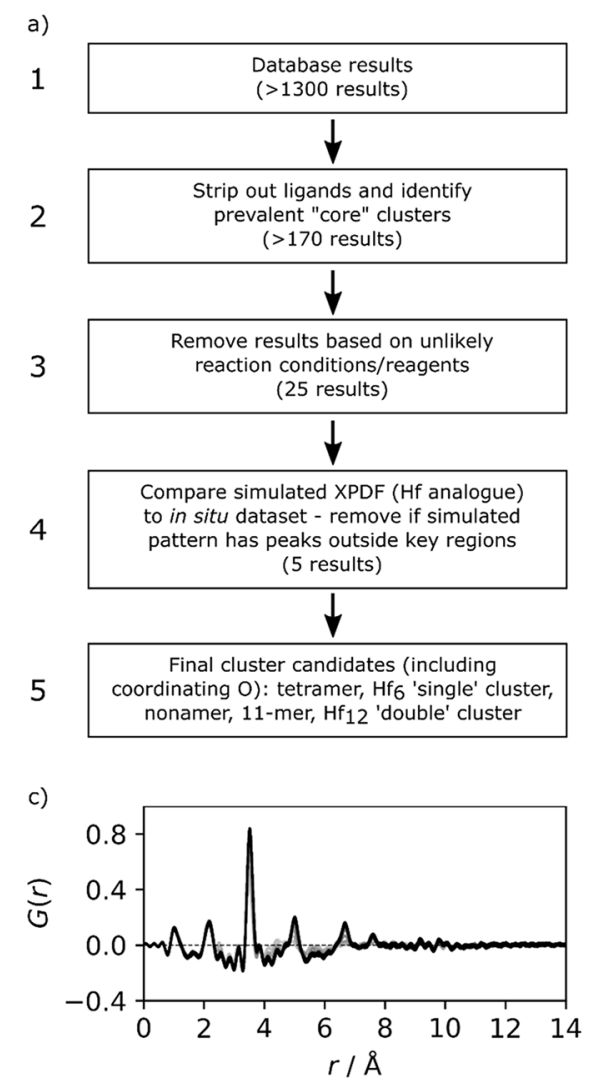

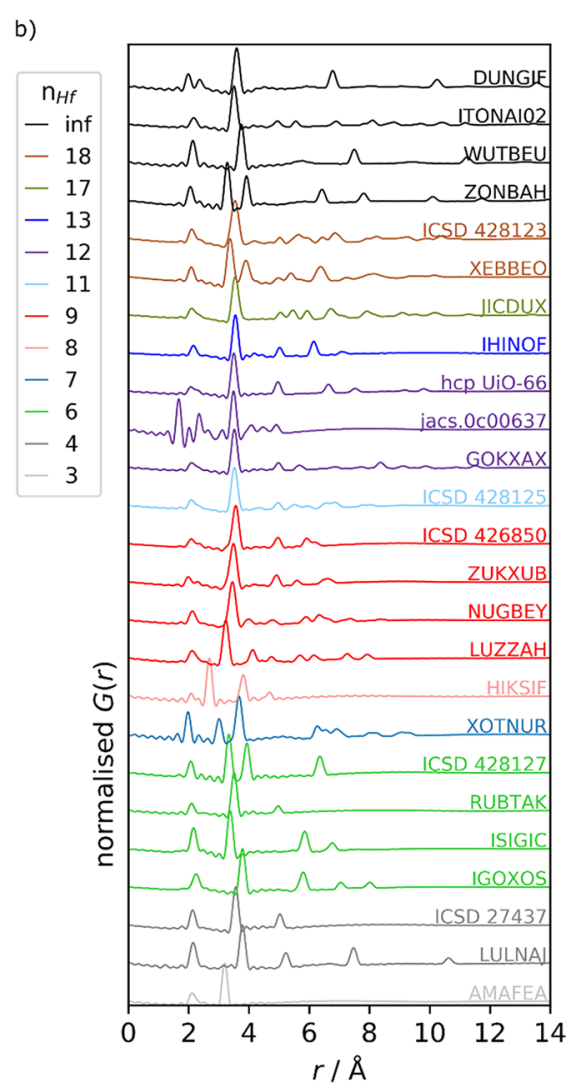

Figure 2. (a) Route used to find an appropriate set of cluster candidates. (b) Simulated XPDF patterns of remaining clusters at step 3 (annotated with their CCDC/ICSD codes), with each data set normalized to its most intense peak; cluster data sets have been color-coded according to the number of $\mathrm{Hf}$ atoms in the cluster $\left(n_{\mathrm{Hf}}\right.$ in the legend). (c) In situ data set of a linker-free reaction in DFW 65:25:10 solvent at 150 ${ }^{\circ} \mathrm{C}$, showing regions of characteristic peaks used as boundaries for step 4. Cluster structure models were obtained from crystal structure files and edited using the VESTA program. ${ }^{79}$ References: $n=3 ;^{37} n=4 ;^{30,80} n=6 ;^{15,39,81,82} n=7 ;^{83} n=8 ;^{11} n=9 ;^{16,24,84,85} n=11 ;^{81} n=12 ;^{17,24,86} n=13 ;^{87} n=17 ;^{51}$ $n=18 ;{ }^{81,88}$ "infinite" structures. ${ }^{19-21,58}$

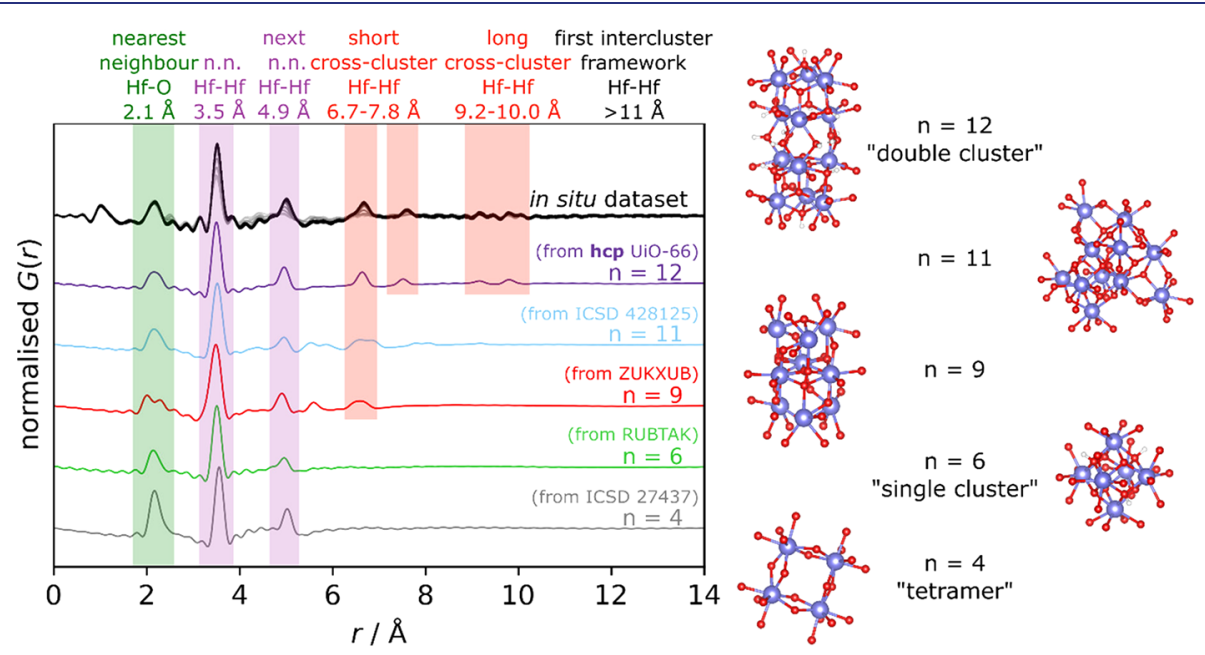

Figure 3. Final cluster options and their simulated XPDF patterns, with key peak areas highlighted, and an in situ data set of a linker-free reaction at $150{ }^{\circ} \mathrm{C}$ for comparison. Cluster structure color scheme: $\mathrm{Hf}$, blue; $\mathrm{O}$, red; $\mathrm{H}$, white. Cluster structure models were obtained from crystal structure files ${ }^{15,24,26,55,81}$ and edited using the VESTA program to give the $\mathrm{Hf}$ analogues and remove peripheral ligands. ${ }^{79}$ Intercluster peaks below $11 \AA$ are not present in our MOFs; in solution, motional averaging will prevent any defined peaks from intercluster interactions.

approach, we carried out a refinement, our model ("the fivecluster model”) including all five core clusters (as in Figure 3) allowing their relative concentrations to vary, against an XPDF measurement of our "baseline" solution of aqueous $\mathrm{HfCl}_{4}(30$ wt $\%$, room temperature). Our refinement converged to give a contribution from the tetramer only [Figure 4a], as expected, ${ }^{26,30,33}$ confirming the viability of this approach, even for structurally closely related clusters.

A significant misfit in the region around $4.5 \AA$ was found in this initial refinement [Figure $4 a$ ] that was not well fit by the isolated tetramer cluster model. This initial model did not take an account of the likely structuring of water as a coordination 

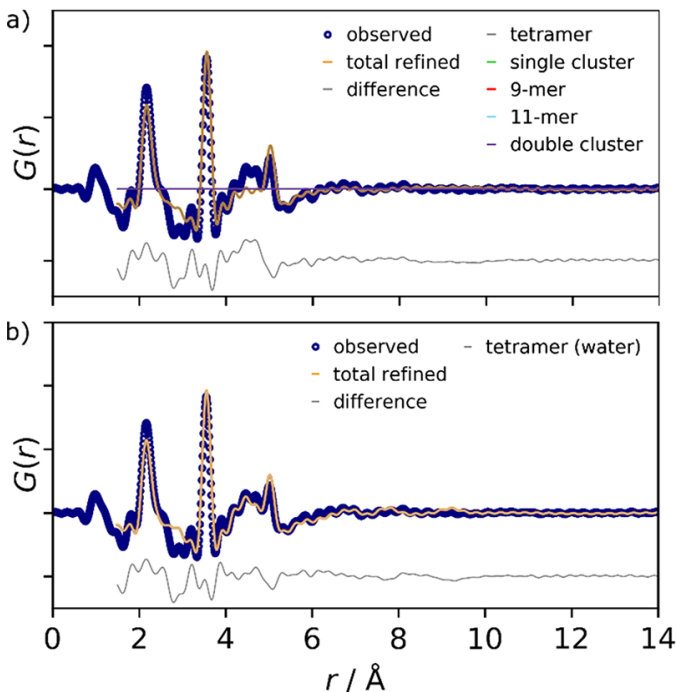

Figure 4. XPDF studies of $\mathrm{HfCl}_{4}$ in water. Refinement of (a) the fivecluster model against the XPDF data set of $\mathrm{HfCl}_{4}$ in water at room temperature $\left(R_{\mathrm{w}}=0.346\right)$ (scale factors of all species except the tetramer are less than $0.05 \%$ of the scale value of the tetramer) and (b) the tetramer $\cdot \mathrm{H}_{2} \mathrm{O}$ model ${ }^{26}$ against the XPDF data set of $\mathrm{HfCl}_{4}$ in water at room temperature $\left(R_{\mathrm{w}}=0.319\right)$.

sphere around the cluster. ${ }^{34,35}$ We therefore augmented our tetramer model by including an additional coordination shell of 24 water molecules, with the oxygens placed using the locations of water and chloride in the crystal structure of zirconyl chloride octahydrate [Figure S3]. ${ }^{26,32}$ The simulated $\mathrm{XPDF}$ of this augmented tetramer model, "tetramer $\cdot \mathrm{H}_{2} \mathrm{O}$ ", shows both a significant intensity at about $4.5 \AA$ and broader, weaker contributions at 7-9 $\AA$, both due to non-nearestneighbor Hf (cluster)-O (solvent) distances. Refining the tetramer $\cdot \mathrm{H}_{2} \mathrm{O}$ cluster model against the experimental XPDF data [Figure $4 \mathrm{~b}$ ] improved the quality of fit $\left(R_{\mathrm{w}}[\right.$ tetramer] $=$ 0.345 vs $R_{\mathrm{w}}$ [tetramer $\left.\cdot \mathrm{H}_{2} \mathrm{O}\right]=0.319$ ), with the fit particularly improved in the aforementioned region around $4.5 \AA$ [Figure $4 \mathrm{~b}$ ], suggesting that in solution there is a highly structured coordination sphere of water around the $\left[\mathrm{Hf}_{4}(\mathrm{OH})_{8}\left(\mathrm{H}_{2} \mathrm{O}\right)_{16}\right]^{8+}$ cluster.

Hf Behavior in DMF/Formic Acid/Water Solvent. Once we had confirmed the viability of our method to differentiate between structurally closely related clusters, we set out to elucidate the behavior of the system throughout the reaction in DFW 65:25:10 solvent, both with and without terephthalic acid (BDC) linker and at different temperatures. In particular, we investigated the conditions that trigger a difference in cluster nuclearity, which we have previously shown to result in different UiO-66(Hf) MOF structures, ${ }^{17,55}$ to try and identify at what stage of the reaction these differences occur. We began with a room-temperature experiment, to compare the clusters that formed in the aqueous-only $\mathrm{HfCl}_{4}$ solution with those found in a solution comprising DMF, formic acid, and water.

Refinement of the five-cluster model against the roomtemperature DFW 65:25:10 solvent data set [Figure S4a] gave the best fit with a mixture of only the tetramer and the fcu $\mathrm{UiO}-66$ type $^{15}$ hexanuclear single cluster [Figure 3], with no significant contribution from any higher-nuclearity species. A high degree of correlation was however observed between the proportions of the 11-mer and the single cluster owing to similarities between the XPDF patterns of the species. However, the correlations were reduced and the fit was improved when the tetramer $\cdot \mathrm{H}_{2} \mathrm{O}$ was used instead of the tetramer in the five-cluster model [Figure S4b], suggesting that, rather than extra species being present, the refinement was using contributions from the 11-mer to fit the weak signals arising from the solvent restructuring at 7-9 $\AA$ [these signals can be seen in Figure S4b]. The refinement was then repeated with the tetramer $\cdot \mathrm{H}_{2} \mathrm{O}$ and the single cluster only [Figure $5 \mathrm{~b}$ ],
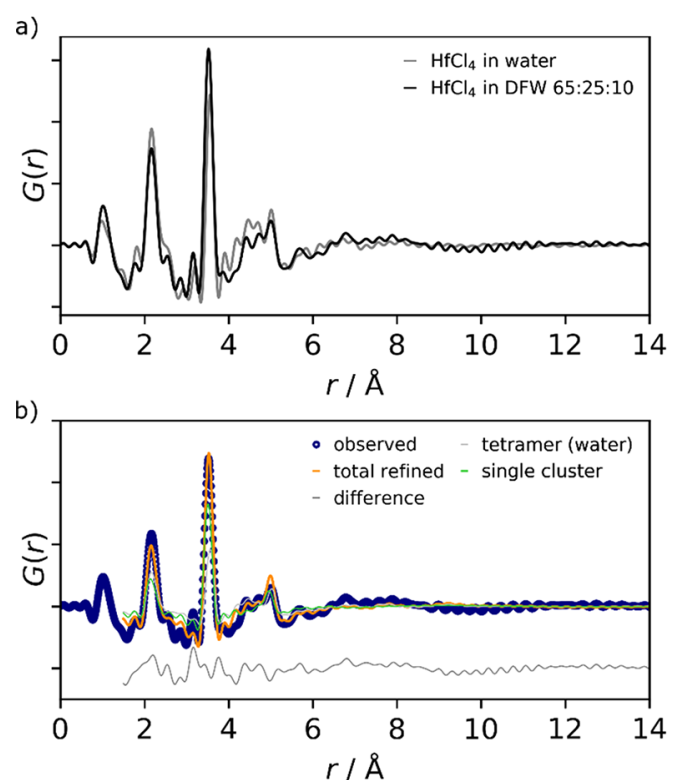

Figure 5. $\mathrm{HfCl}_{4}$ in DMF/formic acid/water: (a) comparison of data sets of $\mathrm{HfCl}_{4}$ in water and $\mathrm{HfCl}_{4}$ in DFW 65:25:10 solvent and (b) refinement of both the tetramer $\cdot \mathrm{H}_{2} \mathrm{O}$ and single cluster models, against the XPDF data set of $\mathrm{HfCl}_{4}$ in DFW 65:25:10 solvent at room temperature $\left(R_{\mathrm{w}}=0.259\right)$.

giving a good fit with a 58:42 ratio of scale factors (albeit correlated), which was an improvement on that obtained from the refinement of a mixture of the tetramer (without water) and the single cluster [Figure S4c], again suggesting that some solvent restructuring remains.

Compared to the XPDF of $\mathrm{HfCl}_{4}$ in water, which contains only the tetramer cluster, the XPDF of room-temperature $\mathrm{HfCl}_{4}$ in DFW 65:25:10 solvent (65:25:10 $\mathrm{V} / \mathrm{V}$ dimethylformamide (DMF)/formic acid/water) has a lower intensity at $2.1 \AA$, implying a lower number of $\mathrm{Hf}-\mathrm{O}$ nearest neighbors relative to $\mathrm{Hf}-\mathrm{Hf}$ nearest neighbors: the tetramer has a ratio of 4:1 Hf-O/Hf-Hf nearest neighbors, whereas for the single cluster this ratio is $2: 1$. There is also less intensity at $4.5 \AA$, suggesting a reduced water coordination shell [ Figure 5a)].

Additional refinements were performed to explore the contributions by the tetramer and single cluster separately, and the extent of solvent reorganization [Figure S5a,b]. These results overall indicated that the solvent structuring due to water is less obvious than that seen in the XPDF pattern of the tetramer $\cdot \mathrm{H}_{2} \mathrm{O}$ in water, even though water is in large excess compared to $\mathrm{Hf}$ in our sample of $\mathrm{HfCl}_{4}$ in DFW 65:25:10 solvent (1:232:183:153 molar ratio $\mathrm{Hf} / \mathrm{DMF} /$ formic acid/ water). Evidence of a longer-range structure within the solvent can be seen in the long-period modulation of intensity and the small peak at $6.8 \AA$, which are both a much better fit by the tetramer $\cdot \mathrm{H}_{2} \mathrm{O}$ model, which includes some local solvent structuring, unlike the single cluster model. Similar long 
a)

c)
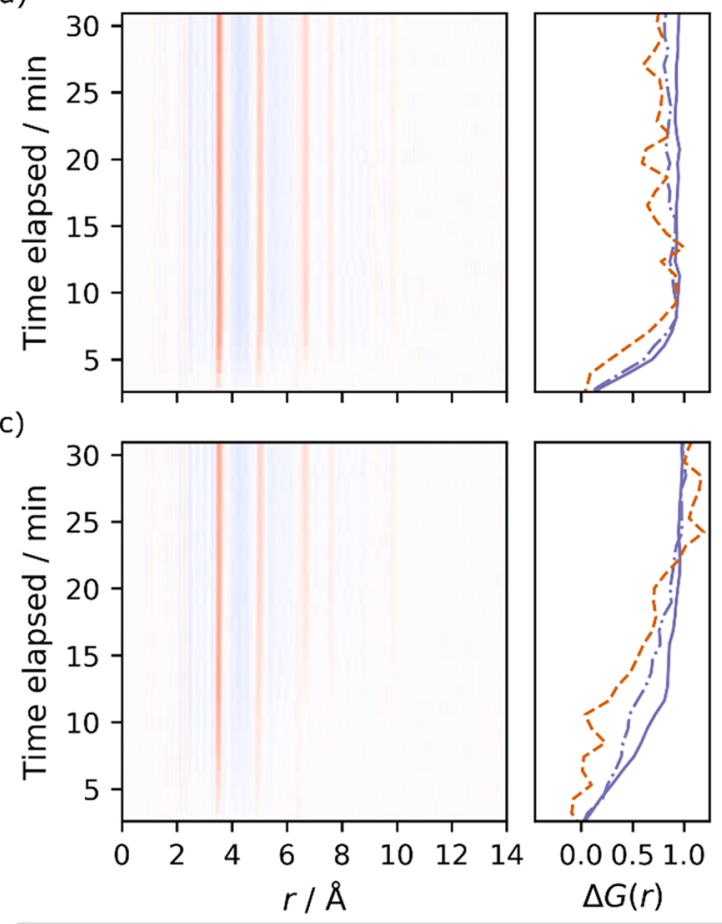

b)

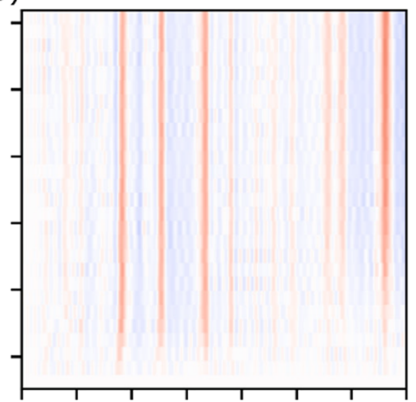

d)
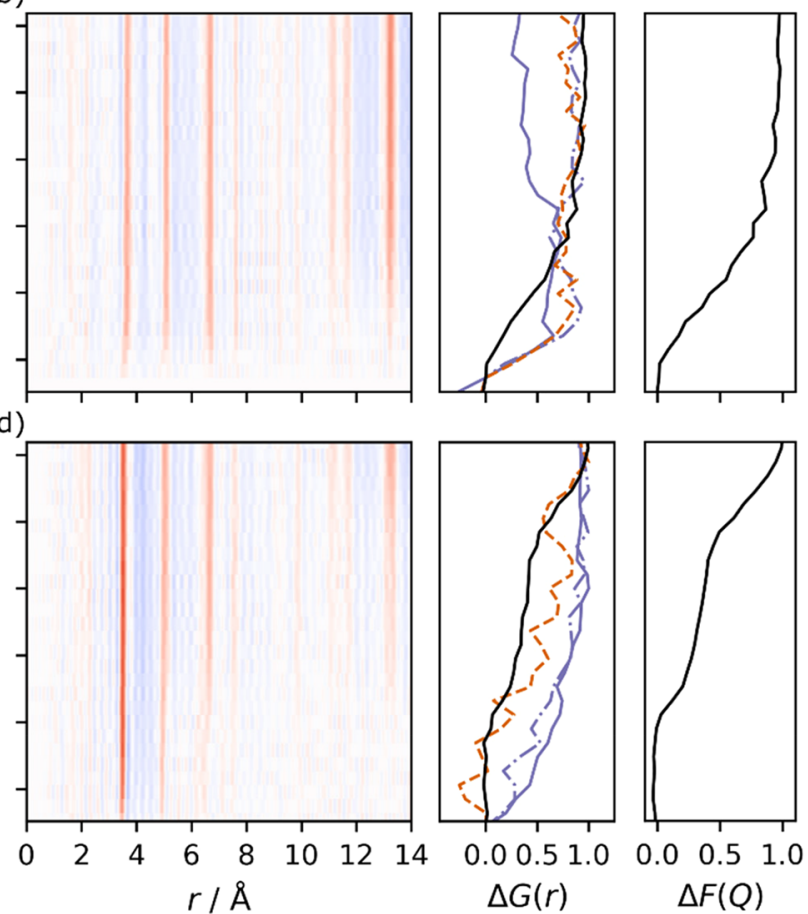
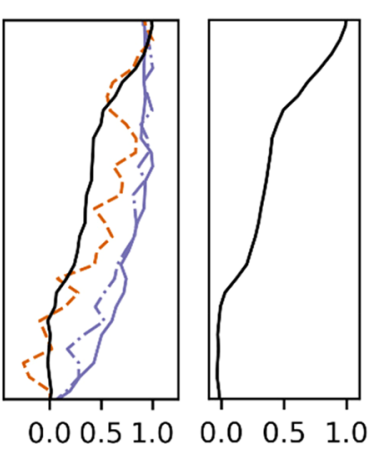

$\Delta G(r)$

$\Delta F(Q)$

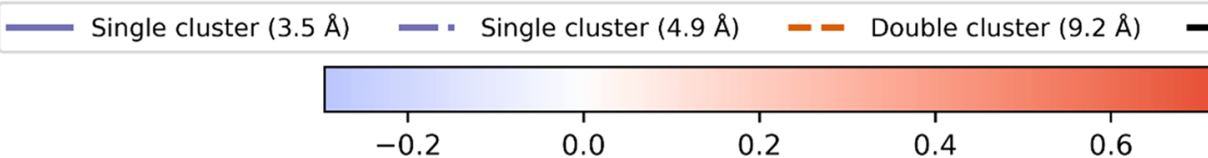

Figure 6. Color plots showing the change in the $G(r)$ values over time at 150 and $120{ }^{\circ} \mathrm{C}$ : (a) $150{ }^{\circ} \mathrm{C}$, no $\mathrm{BDC}$ linker; (b) $150{ }^{\circ} \mathrm{C}$, with $\mathrm{BDC}$ linker; (c) $120{ }^{\circ} \mathrm{C}$, no BDC linker; and (d) $120^{\circ} \mathrm{C}$, with BDC linker (Conditions 3-6 in Table 1). $\Delta G(r)_{t}$ is shown to the right of each plot, calculated as $\left[G(r)_{t}-G(r)_{t_{\text {tintial }}}\right] /\left[G(r)_{t}-G(r)_{t_{\text {tintial }}}\right]_{\max }$ (experimental data may continue slightly beyond the bounds of the plots). The crystalline component is analyzed via $F(Q)$ peak tracking, where the change in the intensity of the reflection at $3.01 \AA^{-1}$ is plotted as $\Delta F(Q)$. $G(r)$ intercluster and $F(Q)$ peak tracking are only shown for reactions containing BDC (that is, reactions that form a framework). Experimental data may continue slightly beyond the bounds of the plots.

period intensity modulations have been observed previously in the XPDF of solvated species. ${ }^{36}$

The XPDF analysis of our DFW 65:25:10 solvent data set corroborates that a change of solvent system, without any change in temperature, is already sufficient to cause some degree of cluster aggregation, from the tetramer to the fcu UiO-type single cluster. Some tetramer still remains, potentially due to the solution not reaching complete equilibrium; in other studies, the solutions were allowed to age for several weeks prior to measurement, whereas the time scales between synthesis and measurement in this study were under 6 h. ${ }^{31}$ Neither the $\mathrm{Hf}_{12}$ double cluster, however, nor any other cluster of nuclearity $n>6$ were observed in this study of $\mathrm{HfCl}_{4}$ in DFW 65:25:10. The single cluster species is known to be particularly stable, ${ }^{15,89}$ as well as being found in a wide range of syntheses and conditions, ${ }^{21,90}$ which suggests that changing the type and concentration of modulating acid or the reaction time are not sufficient alone for further cluster aggregation; $^{15,21,29,31,89,90}$ higher temperatures may also be required to encourage the formation of higher-nuclearity clusters. $^{17,55,64}$

Behavior of $\mathrm{Hf}$ in DMF/Formic Acid/Water Solvent at Raised Temperatures. We next investigated the effect of raised temperature on a solution of $\mathrm{HfCl}_{4}$ in the same DFW 65:25:10 solvent. Since our previous work showed that hcp UiO-66(Hf), containing dodecanuclear metal clusters ("double cluster"), required a higher synthesis temperatures compared to fcu UiO-66(Hf), which contains the hexanuclear single cluster, ${ }^{17,55}$ we studied our system at two temperatures: 150 ${ }^{\circ} \mathrm{C}$, the temperature used for our lab syntheses of hcp UiO$66(\mathrm{Hf})$ and hcp UiO-67(Hf), and $120^{\circ} \mathrm{C}$, at which temperature hcp UiO-67(Hf) did not form. ${ }^{17}$ We also investigated the effect of the presence of additional coordinating linkers by performing reactions at the two different temperatures both with and without a terephthalic acid $\left(\mathrm{H}_{2} \mathrm{BDC}\right)$ linker.

For our analysis of these four in situ data sets, we tracked the change in the area of specific key peaks in the XPDF [Figure 6]. The area under a peak corresponding to a correlation between atoms $\mathrm{A}$ and $\mathrm{B}$ in an XPDF data set is a function of the atomic numbers of $\mathrm{A}$ and $\mathrm{B}$, the number of those correlations, and, in the $G(r)$ normalization, $1 / r_{\mathrm{AB}}$. On the basis of our analysis of the room-temperature data sets in different solvents [Figure 5a and Figures S4 and S5], we established that the area under the peak at $3.5 \AA$ (the nearest neighbor Hf-Hf correlation) is larger for the single cluster than for the tetramer (in the single cluster, each Hf has four nearest neighbors, while in the tetramer, each Hf has only two nearest neighbors). In all our in situ reactions, the area under this peak initially increases, corresponding to a reduction in the proportion of tetramer. This is further corroborated by the increase in the area under the peak at $4.9 \AA$ at the start of the 


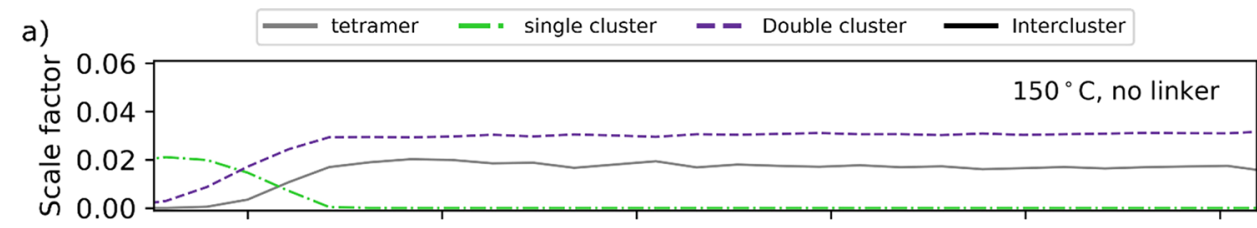

b)

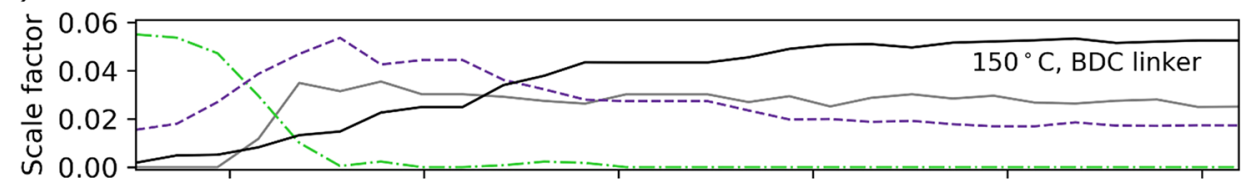

c)

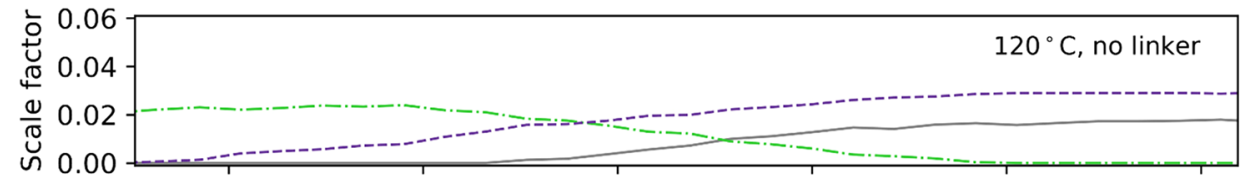

d)

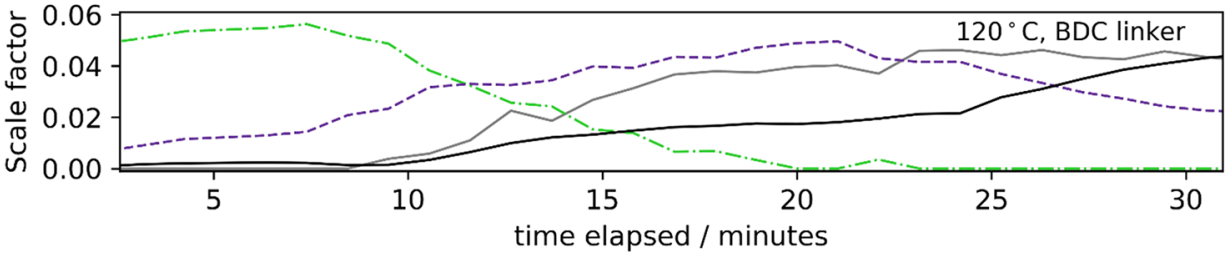

Figure 7. Tracking refined proportions of cluster species (omitting nonamer and 11-mer) over time for the four in situ reactions: $(\mathrm{a}) 150{ }^{\circ} \mathrm{C}$, no $\mathrm{BDC}$ linker; (b) $150^{\circ} \mathrm{C}$, with BDC linker; (c) $120^{\circ} \mathrm{C}$, no BDC linker; and (d) $120^{\circ} \mathrm{C}$, with BDC linker. The uncertainty margin for each species is omitted due to correlation.

reaction, corresponding to an increase in the amount of nextnearest neighbor $\mathrm{Hf}-\mathrm{Hf}$ interactions, which also indicates the formation of clusters other than the tetramer. The growth of the peaks at 3.5 and $4.9 \AA$ indicates that species of higher nuclearity than the tetramer are forming, but this analysis alone cannot distinguish between the growth of single cluster and the $\mathrm{Hf}_{12}$ double cluster. However, these peaks generally precede the growth of the peak at $9.2 \AA$, which is only seen in the $\mathrm{Hf}_{12}$ double cluster [Figure 3], allowing us to distinguish the appearance of the double cluster separate from the single cluster. While the tetramer is found alongside the single cluster in our room temperature experiments, the elevated-temperature data suggests that, once the temperature is raised, higher nuclearity clusters are favored (as expected ${ }^{35}$ ) over the tetramer.

Figure 6 shows the change in $G(r)$ over time for the reactions both with and without a linker at the two different elevated temperatures. The change in the area of the key peaks, $\Delta G(r)$, is also shown and labeled as follows. The peaks at 3.5 and $4.9 \AA$ are labeled a "single cluster", as they are more intense in the single cluster than in the tetramer; the peak at $9.2 \AA$ is only present for the double cluster; and the peak at 13.2 A corresponds to an intercluster separation distance. We normalized the intensity of each peak by dividing the maximum difference, $\Delta G(r)=\frac{G(r)_{t}-G(r)_{t_{\text {tinitial }}}}{\left[G(r)_{t}-G(r)_{t_{\text {initial }}}\right]_{\max }}$, to better display the changes over the observed course of the reaction.

As a complementary analysis, we also performed refinements in the same manner as for the room temperature reactions, using the five-cluster model for refinements of each time step in the data sets. These initial refinements [Figure S6] included no significant contribution from the nonamer and 11-mer throughout the reactions, meaning that only the tetramer, single cluster, and double cluster are present in measurable concentrations. A second analysis was then performed with only these three clusters (i.e., omitting the nonamer and 11mer) [Figure 7]. In these refinements of the heated in situ reactions, we always observe the single cluster first, with the double cluster emerging at later stages; this agrees with our analysis from the peak-tracking data.

Due to the high correlation between the proportions of these remaining cluster species, the exact ratios of these species as the reactions progressed could not be confidently determined using this method. However, from the cluster proportions obtained from this refinement [Figure 7], in all of the in situ reactions, the growth in the concentration of the double cluster occurs alongside a reduction in the amount of single cluster, and there is no delay between the loss of single cluster and the formation of the double cluster. This suggests that the double cluster forms by the direct combination of single clusters rather than forming directly from the tetramer (a pathway not involving the single cluster) or requiring the breakdown of single clusters into lower nuclearity clusters prior to the formation of the double cluster.

Initial refinements showed an increase in tetramer concentration with reaction time, which is extremely unlikely as higher temperatures favor higher nuclearity clusters. We found that the amount of tetramer is highly correlated to the amount of double cluster or framework present and increases at similar times. It is possible that the tetramer is included to compensate for some peak broadening or distortion, as has been observed in $\mathrm{Zr}$ and $\mathrm{Hf}$ clusters upon heating. ${ }^{91,92}$ The tracked peak areas, however, do not have this issue, as this peak broadening will not affect the integrated peak area. Thus, both methods of analysis are complementary. 
a)

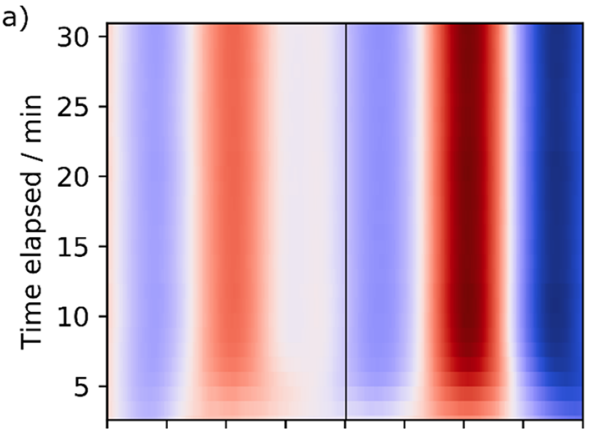

c)

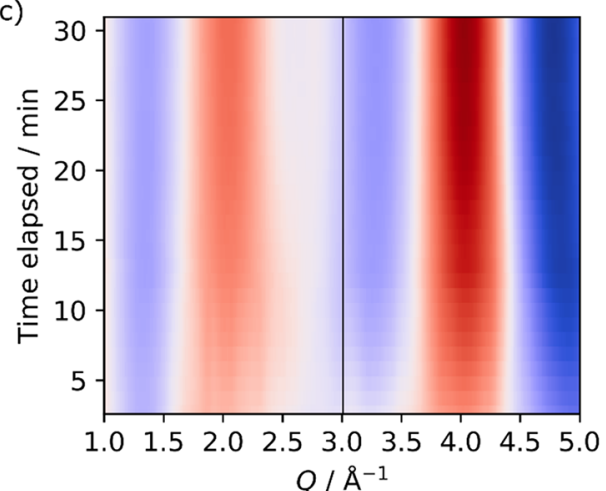

b)

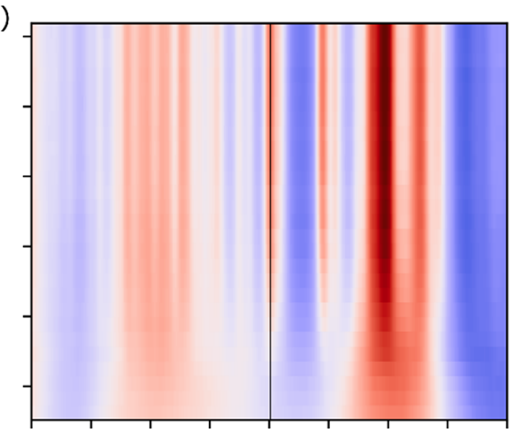

d)

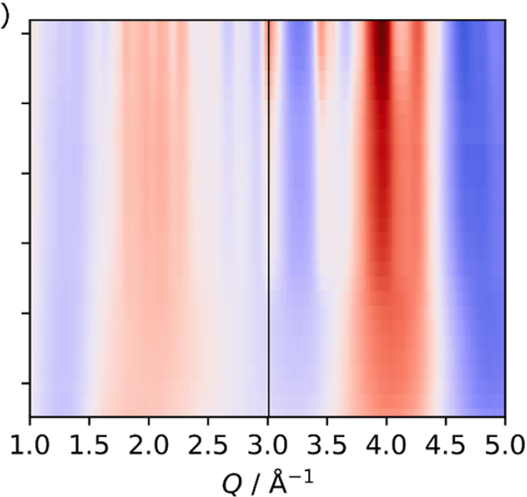

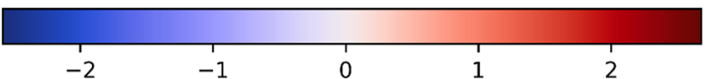

Figure 8. $2 \mathrm{D}$ data sets of $F(\mathrm{Q})$ for the in situ data sets over time, at (a) $150{ }^{\circ} \mathrm{C}$, no BDC linker; (b) $150{ }^{\circ} \mathrm{C}$, with $\mathrm{BDC}$ linker; (c) $120{ }^{\circ} \mathrm{C}$, no $\mathrm{BDC}$ linker; and (d) $120^{\circ} \mathrm{C}$, with BDC linker. At $3.01 \AA^{-1}$, the location of the Bragg peak tracked in Figure 6 for those data sets containing the BDC linker, is shown on the plots with a thin black line.

Peaks beyond $11 \AA$, when considered against our five-cluster model, only arise from intercluster distances in an interlinked framework [Figure 3]; in our systems, these peaks, such as that at $13.2 \AA$, correspond to clusters joined by BDC linkers. In the $\mathrm{BDC}$-containing reactions at both temperatures, the growth of these intercluster peaks occurs both following, and at a slower rate than, the intracluster peaks. This shows that intercluster coordination occurs following, rather than simultaneously with, the cluster formation, in keeping with our previous work, which suggested that the noncrystalline precursor of the framework (i.e., the cluster material) is in large excess prior to the framework coordination and growth. ${ }^{17}$

To further understand the behavior of the linker-containing systems (i.e., with the potential to form a crystalline MOF framework), we also examined the reciprocal-space structure factor, $F(Q)$ [Figure S8], and tracked the changes at $3.01 \AA^{-1}$ [shown in Figure 6 for the BDC-containing reactions as $\Delta F(Q)$, defined as the change in $F(Q)$ between time $t_{\text {initial }}$ and time $t$, divided by the maximum change in $F(Q)$ over the course of the reaction] as an indication of the formation of hcp $\mathrm{UiO}-66(\mathrm{Hf})$, with this reflection at $3.01 \AA^{-1}$ being indexed to the intense and characteristic $\{063\}$ Bragg reflection of the crystalline hcp framework. The growth of this Bragg peak coincides with the growth of the framework intercluster peaks, including that at $13.2 \AA$, in the XPDF [Figure 6], meaning that the connection of the clusters into a framework occurs simultaneously with the crystal formation, rather than first forming as an amorphous linked-cluster polymeric phase with subsequent rearrangement to become crystalline.

The changes in the $F(Q)$ data indicate that the hcp UiO$66(\mathrm{Hf})$ material is formed in both the BDC-150 and the BDC-
120 reactions [Figures $6 \mathrm{~b}, \mathrm{~d}$ and 8 ]. However, there appears to be two stages to the growth in the framework at $120{ }^{\circ} \mathrm{C}$ [Figure 6d], shown both by the tracked intercluster peak in $G(r)$ at $13.2 \AA$ and by the changes in the $3.01 \AA^{-1}$ reflection in $\Delta F(Q)$. The first stage occurs once some amount of double cluster has formed, with a sudden increase in the intensity of the reflection at $3.01 \AA^{-1}$ at c. $11.5 \mathrm{~min}$ [Table S1], indicating rapid framework growth. But, after an initial increase in peak area, the rate of framework formation slows and plateaus around $18.9 \mathrm{~min}$ (likely limited by the amount of available double clusters, which does not reach a maximum until around $25.1 \mathrm{~min}$, according to the $G(r)$ tracking). The second stage, with fastest framework growth at c. $26.1 \mathrm{~min}$, occurs once the double cluster peaks in the $G(r)$ have reached their maximum (i.e., once there is significant excess of the "free" double cluster), with a higher rate, as the amount of double cluster is no longer limiting.

These reactions were performed with different concentrations and a different solvent ratio to the lab syntheses, in order to work in the in situ capillary. In order to determine whether the results produced in situ could be representative of reactions occurring in a standard lab synthesis, we repeated the reactions in a laboratory vessel with the same concentrations and solvent ratio as those used in situ. Both reactions in the laboratory vessel, both at 150 and $120^{\circ} \mathrm{C}$, produced hcp UiO66(Hf), showing that the in situ experiments have the same outcome as a lab synthesis [Figure S7]. Although we previously assumed that a lab synthesis at $120^{\circ} \mathrm{C}$ would not produce the hcp material, in keeping with the results for hcp UiO$67(\mathrm{Hf}),{ }^{17}$ we were inspired by the success of the lab synthesis based on the in situ conditions to attempt a synthesis at $120^{\circ} \mathrm{C}$ 
on the basis of the ex situ conditions used in our previous work to synthesize hcp UiO-66(Hf). ${ }^{55}$ This synthesis also produced the hcp phase [Figure S7]. This result shows that the insights obtained by our in situ study can be used to inspire new and successful lab-based syntheses.

\section{DISCUSSION}

This investigation using X-ray pair distribution function analysis provides previously unknown insights into the formation of Hf metal clusters in solution, both as molecular clusters and in the synthesis of hcp UiO-66(Hf) MOFs. XPDF has been previously used in situ to show the formation of MOF crystallites and to examine the behavior of clusters within an existing MOF framework; ${ }^{57,91}$ we take this powerful technique one step further to show the cluster aggregation in solution prior to and during MOF crystallization.

The results obtained here are not directly comparable to a standard lab-based synthesis, due to the difference in conditions required to increase the signal-to-noise when performing the experiment in a capillary rather than a standard lab reaction vessel. To compensate for the smaller reactor volume, higher concentrations are used. The materials produced in situ in this work are nevertheless consistent with those produced ex situ in a standard lab reaction. This in situ investigation can therefore be used to work toward a better understanding of the solution formation of Hf MOFs even in lab syntheses.

Role of Acid. In this paper, we have shown that, in water, $\mathrm{HfCl}_{4}$ forms the tetramer cluster $\left[\mathrm{Hf}_{4}(\mathrm{OH})_{8} \cdot 16 \mathrm{H}_{2} \mathrm{O}\right]^{8+}$, surrounded by a structured coordination shell of water, as expected at room temperature. With a change of solvent system to DMF/formic acid/water, we obtained a mixture of the tetramer and the single cluster (with a core of $\left[\mathrm{Hf}_{6}\left(\mu_{3^{-}}\right.\right.$ $\left.\left.\mathrm{O})_{4}\left(\mu_{3}-\mathrm{OH}\right)_{4}\right]\right)$, with less structured solvent surrounding the clusters. This suggests that (alongside the DMF solvent) the acid is a critical species in causing the formation of the single cluster. However, in this room-temperature experiment, both the tetramer $\cdot \mathrm{H}_{2} \mathrm{O}$ and the single cluster coexisted in solution, even though both water and formic acid were in large excess (modulator/metal molar ratio of 183:1). This contrasts with the analysis in a previous XPDF investigation (of $\mathrm{Zr}$ species rather than $\mathrm{Hf}$ ), which suggested that solutions of $\mathrm{ZrCl}_{4}$ in either $\mathrm{DMF} / \mathrm{HCl}$ (37 wt \% in water) solvent (1:10.3:41.5 molar ratio metal/acid/water) or in $\mathrm{DMF} / \mathrm{H}_{2} \mathrm{O}$ solvent without added acid (1:28.8 molar ratio metal/water) produced predominantly the single cluster. ${ }^{57}$ Although the hydrolysis reactions necessary for cluster interconversion are known to be kinetically hindered, ${ }^{40}$ that study employed neither heating nor aging to overcome these kinetic limitations, so it is surprising that a mixture of single cluster and tetramer was not observed, especially given the lower concentrations of acid and water relative to metal in that study. ${ }^{57}$

Our observation in this work of the importance of acid to the formation of the single cluster is corroborated by an EXAFS study, ${ }^{31}$ which revealed that the addition of acetic acid to the tetramer in aqueous solution triggers a rearrangement via (too short-lived to be identifiable) an intermediate to form the single cluster. In the EXAFS study, a mixture of the two clusters (as we observed here) was only seen with modulator/ metal ratios below 10:1, which is a far smaller ratio than in our work, despite acetic acid being less reactive than the formic acid modulator we use. ${ }^{40}$ This difference is likely because the reaction solutions in the EXAFS study were aged for weeks prior to measurement in order to obtain equilibrium, which will greatly affect the degree of cluster hydrolysis and conversion.

Role of Water. This paper shows for the first time the formation of the $\mathrm{Hf}_{12}$ double cluster from the $\mathrm{Hf}_{6}$ single cluster. This conversion could be achieved via the hydrolysis reactions common to these $\mathrm{Hf}$ and $\mathrm{Zr}$ species, via terminal hydroxide groups on the single clusters ${ }^{55}$ joining clusters together to give the 12-mer, with its characteristic "belt" of six $\mu_{2}-\mathrm{OH}$ groups.

The single cluster has the formula $\left[\mathrm{Hf}_{6} \mathrm{O}_{4}(\mathrm{OH})_{4}\right] \mathrm{L}_{24}$ and the double cluster is $\left[\mathrm{Hf}_{12} \mathrm{O}_{8}(\mathrm{OH})_{8}(\mathrm{OH})_{6}\right] \mathrm{L}_{36}$ (or the equivalent $\left.\left[\mathrm{Hf}_{6} \mathrm{O}_{4}(\mathrm{OH})_{4}\right]_{2}(\mathrm{OH})_{6} \mathrm{~L}_{36}\right)$, where, in our BDC-free solutions, each terminating singly coordinating $\mathrm{L}$ group could either be half of one bidentate formate anion (as formate takes up two coordination sites) or the combination of one metal-bound $\mathrm{OH}$ and one metal-bound $\mathrm{H}_{2} \mathrm{O} .{ }^{55}$ The cluster-joining reaction could therefore, for example, take the form of $2\left[\mathrm{Hf}_{6} \mathrm{O}_{4}(\mathrm{OH})_{4}\right]$ $\mathrm{L}_{18}(\mathrm{OH})_{3}\left(\mathrm{H}_{2} \mathrm{O}\right)_{3} \rightarrow\left[\mathrm{Hf}_{12} \mathrm{O}_{8}(\mathrm{OH})_{8}(\mathrm{OH})_{6}\right] \mathrm{L}_{36}+6 \mathrm{H}_{2} \mathrm{O}$, i.e., three metal-coordinated terminating $\mathrm{OH}$ groups on each single cluster could form the "belt" of six $\mu_{2}-\mathrm{OH}$, releasing six metalcoordinated water molecules. The joining of clusters alone would give an entropy penalty when considering $\Delta G$ for the reaction-this release of water molecules could alleviate the entropy penalty or even make the cluster joining entropically favorable. While this release of water may seem counterintuitive to our previous observation that water in the synthesis is required for the formation of hcp UiO frameworks, ${ }^{17,55}$ we note that this cluster-joining reaction requires at least $3 \mathrm{~L}=$ $(\mathrm{OH})$ and $3 \mathrm{~L}=\left(\mathrm{H}_{2} \mathrm{O}\right)$ groups on each single cluster (that is, a maximum of $18 / 24 \mathrm{~L}$ sites being coordinated by carboxylate groups); potentially, with less water in the synthesis, insufficient water is present, either in solution or as terminating groups on the clusters, to permit this cluster joining.

These two observations in this work, of the formation conditions of the single cluster and of the double cluster, therefore help to explain why both water and formic acid are necessary in forming hcp $\mathrm{UiO}$ frameworks: formic acid is crucial for the formation of the single clusters, while water is also necessary in order for these single clusters to join to form the double clusters of the hcp framework.

Role of Temperature. This paper also shows that the double cluster requires elevated temperatures to form. Compared with studies that did not demonstrate any interconversion between presynthesized single and double molecular clusters at room temperature, ${ }^{64}$ our observation demonstrates that double clusters can form from single clusters, but that that elevated temperatures are necessary. This is in keeping with our earlier work showing that the hcp UiO-67(Hf) framework, containing the double cluster, requires a higher temperature to form compared to the fcu framework. ${ }^{17}$

In this work, we chose to examine the behavior of our reaction mixtures at two elevated temperatures: 150 and 120 ${ }^{\circ} \mathrm{C}$. By carrying out the reactions at a lower temperature, any kinetically limited processes - such as hydrolysis reactions ${ }^{40}$ should be slowed down. In both reactions carried out at 120 ${ }^{\circ} \mathrm{C}$, the growth of all peaks, especially the intracluster peaks, was significantly slower than that at $150{ }^{\circ} \mathrm{C}$ (the $3.5,4.9$, and $9.2 \AA$ peaks reached their maximum at 22.4, 29.5, and 26.3 min, respectively, for the no-BDC reaction at $120{ }^{\circ} \mathrm{C}$, compared to $10.1,9.3$, and $11.3 \mathrm{~min}$ for the no-BDC reaction at $150{ }^{\circ} \mathrm{C}$ [Table $\left.\mathrm{S} 1\right]$ ), suggesting that these cluster reactions 
(including the formation of the double cluster from single clusters) are indeed kinetically limited. Despite the slower transformation at lower temperatures, we observed no additional cluster species. The formation of the 9- or 11-mer would require additional $\mu_{3}$-bridging $\mathrm{O}$ and $\mathrm{OH}$, which are disfavored at lower temperatures, ${ }^{35}$ particularly once a cluster is saturated with terminating coordinating groups, ${ }^{81}$ whereas the $\mu_{2}-\mathrm{OH}$ bridging in the $\mathrm{Hf}_{12}$ cluster could occur via a much more straightforward nucleophilic attack of $\mathrm{OH}^{38}$ from one cluster to another. Thus, at both 150 and $120{ }^{\circ} \mathrm{C}$, the double cluster is obtained preferentially to other high-nuclearity clusters.

Elevated temperatures also thermodynamically favor processes that result in an increase in entropy. From our discussion of the role of water, the formation of the double cluster is one such process, due to the increase in entropy from the release of structured water upon cluster joining. As well as the metal-coordinated water released as single clusters join to form double clusters, there is also strong evidence for the coordination shells of water-including hydrogen-bonded water-around clusters, ${ }^{55,93}$ some which would also be released upon cluster joining. This indicates that higher temperatures favor the formation of the double cluster for thermodynamic, as well as kinetic, reasons.

Framework Growth and Temperature. Perhaps surprisingly, in this work, we observed that that reactions at both 120 and $150{ }^{\circ} \mathrm{C}$ produced the hcp UiO-66(Hf) framework. This contrasts with our previous work, in which we observed that hcp $\mathrm{UiO}-67(\mathrm{Hf})$ required a temperature of $150{ }^{\circ} \mathrm{C}$ to form (and not $120{ }^{\circ} \mathrm{C}$ ), ${ }^{17}$ and also with the literature, in which fcu $\mathrm{UiO}-67(\mathrm{Hf})$ is usually synthesized at lower temperatures including $120{ }^{\circ} \mathrm{C} .{ }^{94-96}$ As we have shown that, at both temperatures, the double cluster forms, the clue to this behavior could lie in the framework formation. At both of these temperatures, the growth rates of the intracluster peaks do not appear to change with the presence of BDC linker in the reaction. While there is a different concentration of $\mathrm{Hf}$ in the linker-containing reaction mixtures, versus the molecularcluster-only reactions, meaning they cannot be directly compared, this nevertheless suggests that the linkers do not play a critical part in the initial cluster formation and rather become involved later in the reaction through postclusterformation ligand exchange (in agreement with previous research on ligand exchange $\left.{ }^{64,97,98}\right)$.

As a result of the different binding strengths of different carboxylic acids, ${ }^{14,35}$ the low solubility of BDC in DMF/formic acid solutions, ${ }^{17}$ and the ratio of formic acid to BDC in these reactions being in excess of 40:1, it is not surprising that the BDC linkers may be outcompeted initially by formate (or hydroxide) and so coordinate to clusters later in the reaction. As hydroxide groups are more strongly coordinated than carboxylate groups, ${ }^{6,37}$ the joining of the single clusters to form the double cluster could therefore occur before the terminating ligands can exchange (in the linker-containing reactions) for dicarboxylate linkers (which would either "trap" the single cluster species or slow down the cluster conversion). Alongside our discovery that the growth of the crystalline framework occurs simultaneously with, rather than after, the linking of clusters together, this further suggests that, once the clusters link up into a framework, the dicarboxylate linkers are less labile and that dissociation (required for rearrangement) is kinetically and entropically less favorable. This would therefore mean that, despite the lower temperature used here, the successful formation and linking-up of the double cluster determines the formation of the hcp framework over the fcu.

The framework topology is determined by the double clusters, which form at both 150 and $120^{\circ} \mathrm{C}$. The fact that hcp $\mathrm{UiO}-66(\mathrm{Hf})$ forms at $120{ }^{\circ} \mathrm{C}$ even in the less concentrated, laboratory syntheses, whereas hcp UiO-67(Hf) does not, suggests that the nature of the linker-terephthalic acid for UiO-66 and biphenyldicarboxylic acid for UiO-67 frameworks-is key to the formation of the MOF in terms of its ability to coordinate competitively to the clusters. The twostage framework growth of hcp UiO-66(Hf) at $120{ }^{\circ} \mathrm{C}$ described in this work may, however, sheds light on our previous discovery that an $e x$ situ reaction with a UiO-67(Hf) reaction mixture at $120{ }^{\circ} \mathrm{C}$ resulted in a poorly crystalline material ${ }^{17}$ rather than either the fcu or the hcp framework. If that previous ex situ $\mathrm{UiO}-67(\mathrm{Hf})$ reaction mixture follows a similar framework growth pattern to the two-stage pattern observed in this work, then the first stage of framework growth could occur before the cluster aggregation from single to double clusters is complete. This could involve the cluster coordination sites being "blocked" against further attack by exchange of dicarboxylic acid linkers with the clusterterminating ligands, ${ }^{45}$ resulting in a mixture of coordinated single and double clusters, with different and less compatible coordination geometries.

This further suggests that, by adjusting the temperature of the reaction to take advantage of the different rates of cluster condensation and of framework growth, it may be possible to allow more time for the clusters to join together prior to coordination by intercluster linkers, and so obtain "multicluster" species intermediate between the double cluster and previously observed infinite 1-D chains, all based on the $M_{6}$ single cluster unit. ${ }^{9}$

Alongside the previous studies, our work with formic acid corroborates that cluster formation in these $\mathrm{UiO}$ systems is determined by a complex interplay of temperature, aging, concentration of metal salt and the type, and concentration and $\mathrm{p} K_{\mathrm{a}}$ of acid (which can act as a modulator and as directing groups $\left.{ }^{44,81,85}\right)$. The complex processes discussed in this work motivate further exploration to enable understanding in greater detail and hence improved exploitation. With careful control over the timing of linker addition, and consideration of the coordination-site-preferential exchange between linkers and terminating ligands known to occur with molecular double clusters $^{64}$ (particularly involving the ligands at the "narrow" ends of the cluster), ${ }^{17}$ this enhanced understanding of cluster formation in $\mathrm{UiO}$ systems could lead to intentional control of the framework growth, potentially providing routes to ordered mixed-linker frameworks, double-cluster-containing nanosheets such as those we previously reported, ${ }^{17,55}$ or as-yet-unknown multicluster MOFs.

\section{CONCLUSIONS}

In this work, we have demonstrated that XPDF data can successfully capture the precrystalline stages of $\mathrm{Hf} \mathrm{MOF}$ formation during in situ solvothermal reactions, including distinguishing between different metal clusters in solution. We have used this technique to explore the response of $\mathrm{HfCl}_{4}$ to different reaction temperatures and solvents, in particular those used to synthesize the hcp UiO-66(Hf) MOF, using a combination of refinement and peak area calculations to track subtle changes in the XPDF between different systems and over the course of in situ reactions. In water, the dominant 


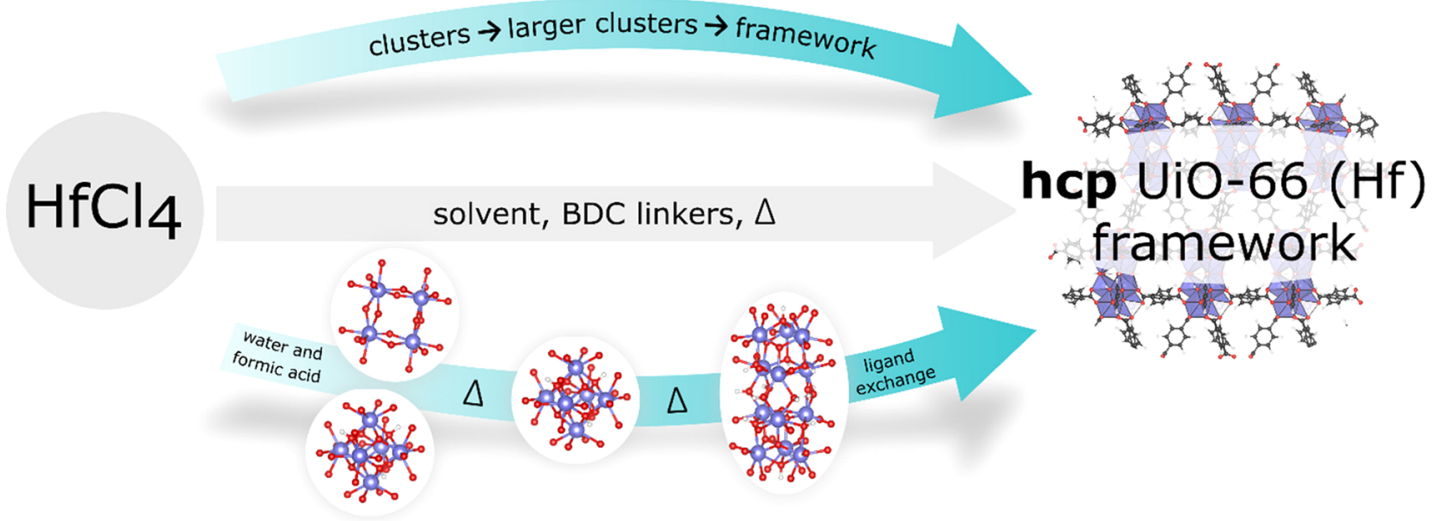

Figure 9. Summary of stages in the formation of hcp UiO-66(Hf) in solvothermal conditions.

cluster form is the tetramer, but in a mixture of DMF, formic acid, and water, it quickly begins to convert to the hexanuclear single cluster form even at room temperature; the formic acid is likely to act as a directing group, but we were not able to identify any intermediates in the transition from tetramer to single cluster. Heating this reaction mixture results in an initial decrease in the proportion of tetramer, followed by the growth of the double cluster alongside a reduction in the amount of single clusters. This provides strong support for a mechanism for double cluster formation directly from pairs of single clusters with $\mu_{2}-\mathrm{OH}$ bridges created between them, rather than forming directly from the tetramer or requiring the single clusters to break down and reform larger clusters. No double clusters were observed at room temperature, suggesting that aggregation to form higher-nuclearity clusters is favored by higher temperatures and the rate of double cluster formation increases with temperature. Once the double clusters form, they then undergo ligand exchange to link together in a framework, with BDC in place of terminating ligands; this framework appears to form directly as a crystalline MOF, with no evidence of a transformation from amorphous to crystalline. $\mathrm{Via}$ this analysis, we propose a mechanism for the formation of hcp UiO-66(Hf) [Figure 9].

The insights we have presented here into the behavior of $\mathrm{Hf}$ (and Zr) MOFs during their synthesis advance our understanding of the formation of these important materials. The formation of the metal clusters prior to the framework coordination and growth is a confirmation that, for these UiO family MOFs, the clusters are indeed the "building units" 4,5 that direct the framework topology, rather than the resultant MOF structure being determined by the clusters and linkers concomitantly. The $\mathrm{UiO}$ family of MOFs are particularly promising candidates for real-world applications, for example, in energy storage devices, ${ }^{53}$ but in order to further unlock their potential, they must be able to be deliberately engineered with application-specific properties. The identity and nature of the metal clusters in the framework greatly influence these properties, and so understanding the mechanisms of their formation is key to designing and engineering new frameworks. This will open up possibilities for the synthesis of as-yet-unrealized $\mathrm{Zr}$ and $\mathrm{Hf}$ MOFs with different cluster species and linkers or even mixed-cluster MOFs.

\section{ASSOCIATED CONTENT}

\section{(s) Supporting Information}

The Supporting Information is available free of charge at https://pubs.acs.org/doi/10.1021/jacs.1c06990.

Figures of schematic of in situ experimental setup at the beamline, refinement of the crystal structure, simulated XPDF patterns, refinements against datasets, tracking refined proportions of cluster species, and PXRD patterns and table of key times in the evolution of peaks during the in situ reactions (PDF)

\section{AUTHOR INFORMATION}

\section{Corresponding Author}

Matthew J. Cliffe - School of Chemistry, University of Nottingham, Nottingham NG7 2RD, United Kingdom; (1) orcid.org/0000-0002-0408-7647;

Email: Matthew.Cliffe@nottingham.ac.uk

\section{Authors}

Francesca C. N. Firth - Yusuf Hamied Department of Chemistry, University of Cambridge, Cambridge CB2 1EW, United Kingdom; (1) orcid.org/0000-0002-1209-2702

Michael W. Gaultois - Department of Chemistry, University of Liverpool, Liverpool L69 7ZD, United Kingdom; (1) orcid.org/0000-0003-2172-2507

Yue Wu - Department of Chemistry, University of Liverpool, Liverpool L69 7ZD, United Kingdom

Joshua M. Stratford - School of Chemistry, University of Birmingham, Birmingham B15 2TT, United Kingdom; C orcid.org/0000-0002-6867-4226

Dean S. Keeble - Diamond Light Source, Didcot OX11 ODE, United Kingdom

Clare P. Grey - Yusuf Hamied Department of Chemistry, University of Cambridge, Cambridge CB2 1EW, United Kingdom; orcid.org/0000-0001-5572-192X

Complete contact information is available at: https://pubs.acs.org/10.1021/jacs.1c06990

\section{Notes}

The authors declare no competing financial interest.

\section{ACKNOWLEDGMENTS}

The authors would like to thank the Diamond Light Source for access and support in the use of the X-ray Pair Distribution Function beamline (I15-1), proposal number EE18630-1. 
F.C.N.F was supported by the Engineering and Physical Sciences Research Council (EPSRC, U.K.) via studentship 1943107. C.P.G. was supported by the EPSRC under the Supergen Consortium and grant EP/N001583/1. M.J.C. acknowledges the School of Chemistry, University of Nottingham, for the award of a Hobday Fellowship. The authors would like to thank Dr. Erlendur Jónsson for his assistance in setting up and modifying scripts for DiffPy-CMI and Dr. Chris Truscott in the Chemical Crystallography service in the Yusuf Hamied Department of Chemistry, University of Cambridge for performing the powder X-ray diffraction measurements.

\section{REFERENCES}

(1) Schoedel, A.; Ji, Z.; Yaghi, O. M. The Role of Metal-Organic Frameworks in a Carbon-Neutral Energy Cycle. Nat. Energy 2016, 1 (4), 16034.

(2) Ke, F.-S.; Wu, Y.-S.; Deng, H. Metal-Organic Frameworks for Lithium Ion Batteries and Supercapacitors. J. Solid State Chem. 2015, 223, 109-121.

(3) Stock, N.; Biswas, S. Synthesis of Metal-Organic Frameworks (MOFs): Routes to Various MOF Topologies, Morphologies, and Composites. Chem. Rev. 2012, 112 (2), 933-969.

(4) Eddaoudi, M.; Moler, D. B.; Li, H.; Chen, B.; Reineke, T. M.; O'Keeffe, M.; Yaghi, O. M. Modular Chemistry: Secondary Building Units as a Basis for the Design of Highly Porous and Robust MetalOrganic Carboxylate Frameworks. Acc. Chem. Res. 2001, 34 (4), 319330.

(5) Kalmutzki, M. J.; Hanikel, N.; Yaghi, O. M. Secondary Building Units as the Turning Point in the Development of the Reticular Chemistry of MOFs. Sci. Adv. 2018, 4 (10), eaat9180.

(6) Ongari, D.; Tiana, D.; Stoneburner, S. J.; Gagliardi, L.; Smit, B. Origin of the Strong Interaction between Polar Molecules and Copper(II) Paddle-Wheels in Metal Organic Frameworks. J. Phys. Chem. C 2017, 121 (28), 15135-15144.

(7) Reinsch, H.; Fröhlich, D.; Waitschat, S.; Chavan, S.; Lillerud, K.P.; Henninger, S.; Stock, N. Optimisation of Synthesis Conditions for UiO-66- $\mathrm{CO}_{2} \mathrm{H}$ towards Scale-up and Its Vapour Sorption Properties. React. Chem. Eng. 2018, 3 (3), 365-370.

(8) Spijksma, G.; Blank, D. H.; Bouwmeester, H. J.; Kessler, V. Modification of Different Zirconium Propoxide Precursors by Diethanolamine. Is There a Shelf Stability Issue for Sol-Gel Applications? Int. J. Mol. Sci. 2009, 10 (11), 4977-4989.

(9) Leubner, S.; Zhao, H.; Van Velthoven, N.; Henrion, M.; Reinsch, H.; De Vos, D. E.; Kolb, U.; Stock, N. Expanding the Variety of Zirconium-based Inorganic Building Units for Metal-Organic Frameworks. Angew. Chem. 2019, 131 (32), 11111-11116.

(10) Bai, Y.; Dou, Y.; Xie, L.-H.; Rutledge, W.; Li, J.-R.; Zhou, H.-C. Zr-Based Metal-Organic Frameworks: Design, Synthesis, Structure, and Applications. Chem. Soc. Rev. 2016, 45 (8), 2327-2367.

(11) Feng, D.; Jiang, H.-L.; Chen, Y.-P.; Gu, Z.-Y.; Wei, Z.; Zhou, H.-C. Metal-Organic Frameworks Based on Previously Unknown $\mathrm{Zr}_{8} / \mathrm{Hf}_{8}$ Cubic Clusters. Inorg. Chem. 2013, 52 (21), 12661-12667.

(12) CSD web interface - intuitive, cross-platform, web-based access to CSD data. Cambridge Crystallographic Data Centre: Cambridge, UK, 2017.

(13) Intorre, B. I.; Martell, A. E. Zirconium Complexes in Aqueous Solution. I. Reaction with Multidentate Ligands. J. Am. Chem. Soc. 1960, 82 (2), 358-364.

(14) Kobyashi, T.; Sasaki, T.; Takagi, I.; Moriyama, H. Zirconium Solubility in Ternary Aqueous System of $\mathrm{Zr}$ (IV)-OH-Carboxylates. J. Nucl. Sci. Technol. 2009, 46 (2), 142-148.

(15) Cavka, J. H.; Jakobsen, S.; Olsbye, U.; Guillou, N.; Lamberti, C.; Bordiga, S.; Lillerud, K. P. A New Zirconium Inorganic Building Brick Forming Metal Organic Frameworks with Exceptional Stability. J. Am. Chem. Soc. 2008, 130 (42), 13850-13851.

(16) Artner, C.; Czakler, M.; Schubert, U. New Zirconium and Zirconium-Titanium Oxo Cluster Types by Expansion or Metal
Substitution of the Octahedral $\mathrm{Zr}_{6} \mathrm{O}_{8}$ Structural Motif. Inorg. Chim. Acta 2015, 432, 208-212.

(17) Cliffe, M. J.; Castillo-Martínez, E.; Wu, Y.; Lee, J.; Forse, A. C.; Firth, F. C. N.; Moghadam, P. Z.; Fairen-Jimenez, D.; Gaultois, M. W.; Hill, J. A.; Magdysyuk, O. V.; Slater, B.; Goodwin, A. L.; Grey, C. P. Metal-Organic Nanosheets Formed via Defect-Mediated Transformation of a Hafnium Metal-Organic Framework. J. Am. Chem. Soc. 2017, 139 (15), 5397-5404.

(18) Malaestean, I. L.; Alıc1, M. K.; Besson, C.; Ellern, A.; Kögerler, P. Solid-State Coexistence of $\left\{\mathrm{Zr}_{12}\right\}$ and $\left\{\mathrm{Zr}_{6}\right\}$ Zirconium Oxocarboxylate Clusters. CrystEngComm 2014, 16 (1), 43-46.

(19) Mouchaham, G.; Cooper, L.; Guillou, N.; Martineau, C.; Elkaïm, E.; Bourrelly, S.; Llewellyn, P. L.; Allain, C.; Clavier, G.; Serre, C.; Devic, T. A Robust Infinite Zirconium Phenolate Building Unit to Enhance the Chemical Stability of Zr MOFs. Angew. Chem., Int. Ed. 2015, 54 (45), 13297-13301.

(20) Guillerm, V.; Ragon, F.; Dan-Hardi, M.; Devic, T.; Vishnuvarthan, M.; Campo, B.; Vimont, A.; Clet, G.; Yang, Q.; Maurin, G.; Férey, G.; Vittadini, A.; Gross, S.; Serre, C. A Series of Isoreticular, Highly Stable, Porous Zirconium Oxide Based MetalOrganic Frameworks. Angew. Chem., Int. Ed. 2012, 51 (37), 92679271.

(21) Waitschat, S.; Reinsch, H.; Stock, N. Water-Based Synthesis and Characterisation of a New Zr-MOF with a Unique Inorganic Building Unit. Chem. Commun. 2016, 52 (86), 12698-12701.

(22) Smith, J. A.; Singh-Wilmot, M. A.; Carter, K. P.; Cahill, C. L.; Lough, A. J.; Knee, C. S. Eight Rare Earth Metal Organic Frameworks and Coordination Polymers from 2-Nitroterephthlate: Syntheses, Structures, Solid-State Luminescence and an Unprecedented Topology. New J. Chem. 2016, 40 (9), 7338-7349.

(23) Bosch, M.; Yuan, S.; Zhou, H.-C. Group 4 Metals as Secondary Building Units: $\mathrm{Ti}, \mathrm{Zr}$, and Hf-Based MOFs. In The Chemistry of Metal-Organic Frameworks: Synthesis, Characterization, and Applications; Kaskel, S., Ed.; Wiley-VCH Verlag GmbH \& Co. KGaA: Weinheim, Germany, 2016; pp 137-170.

(24) Jiang, H.; Zhang, W.; Kang, X.; Cao, Z.; Chen, X.; Liu, Y.; Cui, Y. Topology-Based Functionalization of Robust Chiral Zr-Based Metal-Organic Frameworks for Catalytic Enantioselective Hydrogenation. J. Am. Chem. Soc. 2020, 142 (21), 9642-9652.

(25) Kickelbick, G.; Holzinger, D.; Brick, C.; Trimmel, G.; Moons, E. Hybrid Inorganic-Organic Core-Shell Nanoparticles from Surface-Functionalized Titanium, Zirconium, and Vanadium Oxo Clusters. Chem. Mater. 2002, 14 (10), 4382-4389.

(26) Mak, T. C. W. Refinement of the Crystal Structure of Zirconyl Chloride Octahydrate. Can. J. Chem. 1968, 46 (22), 3491-3497.

(27) Kickelbick, G.; Schubert, U. Hydroxy Carboxylate Substituted Oxozirconium Clusters. J. Chem. Soc. Dalt. Trans. 1999, No. 8, 13011306.

(28) Ekberg, C.; Källvenius, G.; Albinsson, Y.; Brown, P. L. Studies on the Hydrolytic Behavior of Zirconium(IV). J. Solution Chem. 2004, 33 (1), 47-79.

(29) Gross, S.; Kickelbick, G.; Puchberger, M.; Schubert, U. Mono-, Di-, and Trimetallic Methacrylate-Substituted Metal Oxide Clusters Derived from Hafnium Butoxide. Monatsh. Chem. 2003, 134 (8), $1053-1063$.

(30) Clearfield, A.; Vaughan, P. A. The Crystal Structure of Zirconyl Chloride Octahydrate and Zirconyl Bromide Octahydrate. Acta Crystallogr. 1956, 9 (7), 555-558.

(31) Hennig, C.; Weiss, S.; Kraus, W.; Kretzschmar, J.; Scheinost, A. C. Solution Species and Crystal Structure of $\mathrm{Zr}(\mathrm{IV})$ Acetate. Inorg. Chem. 2017, 56 (5), 2473-2480.

(32) Aberg, M.; Furuseth, S.; Selte, K.; Kjekshus, A.; Rakke, T.; Andresen, A. F. An X-Ray Investigation of Some Aqueous Zirconium(IV) Halide, a Hafnium(IV) Chloride, and Some Zirconium(IV) Perchlorate Solutions. Acta Chem. Scand. 1977, 31a, $171-181$.

(33) Muha, G. M.; Vaughan, P. A. Structure of the Complex Ion in Aqueous Solutions of Zirconyl and Hafnyl Oxyhalides. J. Chem. Phys. 1960, 33 (1), 194-199. 
(34) Hagfeldt, C.; Kessler, V.; Persson, I. Structure of the Hydrated, Hydrolysed and Solvated Zirconium(IV) and Hafnium(IV) Ions in Water and Aprotic Oxygen Donor Solvents. A Crystallographic, EXAFS Spectroscopic and Large Angle X-Ray Scattering Study. Dalt. Trans. 2004, No. 14, 2142-2151.

(35) Solovkin, A. S.; Tsvetkova, Z. N. The Chemistry of Aqueous Solutions of Zirconium Salts (Does the Zirconyl Ion Exist?). Russ. Chem. Rev. 1962, 31 (11), 655-669.

(36) Zobel, M.; Neder, R. B.; Kimber, S. A. J. Universal Solvent Restructuring Induced by Colloidal Nanoparticles. Science (Washington, DC, U. S.) 2015, 347 (6219), 292-294.

(37) Boyle, T. J.; Ottley, L. A. M.; Hoppe, S. M.; Campana, C. F. Series of Comparable Dinuclear Group 4 Neo-pentoxide Precursors for Production of $\mathrm{pH}$ Dependent Group 4 Nanoceramic Morphologies. Inorg. Chem. 2010, 49 (23), 10798-10808.

(38) Rao, N.; Holerca, M. N.; Klein, M. L.; Pophristic, V. Computational Study of the $\mathrm{Zr}^{4+}$ Tetranuclear Polymer, $\left[\mathrm{Zr}_{4}(\mathrm{OH})_{8}\left(\mathrm{H}_{2} \mathrm{O}\right)_{16}\right]^{8+}$. J. Phys. Chem. A 2007, 111 (45), 1139511399.

(39) Goberna-Ferrón, S.; Park, D. H.; Amador, J. M.; Keszler, D. A.; Nyman, M. Amphoteric Aqueous Hafnium Cluster Chemistry. Angew. Chem., Int. Ed. 2016, 55 (21), 6221-6224.

(40) Tosan, J. L.; Durand, B.; Roubin, M.; Chassagneux, F.; Bertin, F. Coupled Raman and Infrared Spectroscopic Study of Acetic or Formic Zirconyl Chloride Aqueous Solutions. J. Non-Cryst. Solids 1994, 168 (1-2), 23-32.

(41) Bumstead, A. M.; Cordes, D. B.; Dawson, D. M.; Chakarova, K. K.; Mihaylov, M. Y.; Hobday, C. L.; Düren, T.; Hadjiivanov, K. I.; Slawin, A. M. Z.; Ashbrook, S. E.; Prasad, R. R. R.; Wright, P. A. Modulator-Controlled Synthesis of Microporous STA-26, an Interpenetrated 8,3-Connected Zirconium MOF with the the-i Topology, and Its Reversible Lattice Shift. Chem. - Eur. J. 2018, 24 (23), 61156126.

(42) Griffin, S. L.; Briuglia, M. L.; ter Horst, J. H.; Forgan, R. S. Assessing Crystallisation Kinetics of Zr Metal-Organic Frameworks through Turbidity Measurements to Inform Rapid MicrowaveAssisted Synthesis. Chem. - Eur. J. 2020, 26 (30), 6910-6918.

(43) Wang, X.; Zhang, X.; Li, P.; Otake, K. I.; Cui, Y.; Lyu, J.; Krzyaniak, M. D.; Zhang, Y.; Li, Z.; Liu, J.; Buru, C. T.; Islamoglu, T.; Wasielewski, M. R.; Li, Z.; Farha, O. K. Vanadium Catalyst on Isostructural Transition Metal, Lanthanide, and Actinide Based MetalOrganic Frameworks for Alcohol Oxidation. J. Am. Chem. Soc. 2019, 141 (20), 8306-8314.

(44) Kim, J.; Nam, D.; Kitagawa, H.; Lim, D. W.; Choe, W. Discovery of $\mathrm{Zr}$-Based Metal-Organic Polygon: Unveiling New Design Opportunities in Reticular Chemistry. Nano Res. 2021, 14 (2), 392-397.

(45) Fric, H.; Puchberger, M.; Schubert, U. Contributions to the Structural Chemistry of 2-Amino Alcoholate Derivatives of Titanium and Zirconium Alkoxides and Their Partial Hydrolysis Products. Eur. J. Inorg. Chem. 2008, 2008 (9), 1452-1461.

(46) Kanazhevskii, V. V.; Novgorodov, B. N.; Shmachkova, V. P.; Kotsarenko, N. S.; Kriventsov, V. V.; Kochubey, D. I. Structure of Zirconium Complexes in Aqueous Solutions. Mendeleev Commun. 2001, 11 (6), 211-212.

(47) Lister, B. A. J.; McDonald, L. A. Some Aspects of the Solution Chemistry of Zirconium. J. Chem. Soc. 1952, 4315.

(48) Saku, Y.; Sakai, Y.; Shinohara, A.; Hayashi, K.; Yoshida, S.; Kato, C. N.; Yoza, K.; Nomiya, K. Sandwich-Type $\mathrm{Hf}^{\mathrm{IV}}$ and $\mathrm{Zr}^{\mathrm{IV}}$ Complexes Composed of Tri-Lacunary Keggin Polyoxometalates: Structure of $\left[\mathrm{M}_{3}(\mu-\mathrm{OH})_{3}\left(\mathrm{~A}-\alpha-\mathrm{PW}_{9} \mathrm{O}_{34}\right)_{2}\right]^{9-}(\mathrm{M}=\mathrm{Hf}$ and $\mathrm{Zr})$. Dalt. Trans. 2009, 3 (5), 805-813.

(49) Hu, Y. J.; Knope, K. E.; Skanthakumar, S.; Kanatzidis, M. G.; Mitchell, J. F.; Soderholm, L. Understanding the Role of Aqueous Solution Speciation and Its Application to the Directed Syntheses of Complex Oxidic Zr Chlorides and Sulfates. J. Am. Chem. Soc. 2013, 135 (38), 14240-14248.
(50) Singhal, A.; Toth, L. M.; Lin, J. S.; Affholter, K. Zirconium(IV) Tetramer/Octamer Hydrolysis Equilibrium in Aqueous Hydrochloric Acid Solution. J. Am. Chem. Soc. 1996, 118 (46), 11529-11534.

(51) Sun, Q.; Liu, C.; Zhang, G.; Zhang, J.; Tung, C. H.; Wang, Y. Aqueous Isolation of 17-Nuclear $\mathrm{Zr} / \mathrm{Hf}$ Oxide Clusters during the Hydrothermal Synthesis of $\mathrm{ZrO}_{2} / \mathrm{HfO}_{2}$. Chem. - Eur. J. 2018, 24 (55), 14701-14706.

(52) Wu, H.; Chua, Y. S.; Krungleviciute, V.; Tyagi, M.; Chen, P.; Yildirim, T.; Zhou, W. Unusual and Highly Tunable Missing-Linker Defects in Zirconium Metal-Organic Framework UiO-66 and Their Important Effects on Gas Adsorption. J. Am. Chem. Soc. 2013, 135 (28), 10525-10532.

(53) Xia, W.; Mahmood, A.; Zou, R.; Xu, Q. Metal-Organic Frameworks and Their Derived Nanostructures for Electrochemical Energy Storage and Conversion. Energy Environ. Sci. 2015, 8 (7), 1837-1866.

(54) Sun, H.; Tang, B.; Wu, P. Rational Design of S-UiO-66@GO Hybrid Nanosheets for Proton Exchange Membranes with Significantly Enhanced Transport Performance. ACS Appl. Mater. Interfaces 2017, 9 (31), 26077-26087.

(55) Firth, F. C. N.; Cliffe, M. J.; Vulpe, D.; Aragones-Anglada, M.; Moghadam, P. Z.; Fairen-Jimenez, D.; Slater, B.; Grey, C. P. Engineering New Defective Phases of UiO Family Metal-Organic Frameworks with Water. J. Mater. Chem. A 2019, 7 (13), 7459-7469.

(56) Cliffe, M. J.; Wan, W.; Zou, X.; Chater, P. A.; Kleppe, A. K.; Tucker, M. G.; Wilhelm, H.; Funnell, N. P.; Coudert, F.-X.; Goodwin, A. L. Correlated Defect Nanoregions in a Metal-Organic Framework. Nat. Commun. 2014, 5 (1), 4176.

(57) Xu, H.; Sommer, S.; Broge, N. L. N.; Gao, J.; Iversen, B. B. The Chemistry of Nucleation: In Situ Pair Distribution Function Analysis of Secondary Building Units During UiO-66 MOF Formation. Chem. - Eur. J. 2019, 25 (8), 2051-2058.

(58) Taddei, M.; Van Bokhoven, J. A.; Ranocchiari, M. Influence of Water in the Synthesis of the Zirconium-Based Metal-Organic Framework UiO-66: Isolation and Reactivity of [ $\mathrm{ZrCl}$ $\left.(\mathrm{OH})_{2}(\mathrm{DMF})_{2}\right] \mathrm{Cl}$. Inorg. Chem. 2020, 59 (11), 7860-7868.

(59) Johnstone, D. N.; Firth, F. C. N.; Grey, C. P.; Midgley, P. A.; Cliffe, M. J.; Collins, S. M. Direct Imaging of Correlated Defect Nanodomains in a Metal-Organic Framework. J. Am. Chem. Soc. 2020, 142 (30), 13081-13089.

(60) Noel, N. K.; Congiu, M.; Ramadan, A. J.; Fearn, S.; McMeekin, D. P.; Patel, J. B.; Johnston, M. B.; Wenger, B.; Snaith, H. J. Unveiling the Influence of $\mathrm{pH}$ on the Crystallization of Hybrid Perovskites, Delivering Low Voltage Loss Photovoltaics. Joule 2017, 1 (2), 328343.

(61) Leubner, S.; Stäglich, R.; Franke, J.; Jacobsen, J.; Gosch, J.; Siegel, R.; Reinsch, H.; Maurin, G.; Senker, J.; Yot, P. G.; Stock, N. Solvent Impact on the Properties of Benchmark Metal-Organic Frameworks: Acetonitrile-Based Synthesis of CAU-10, Ce-UiO-66, and Al-MIL-53. Chem. - Eur. J. 2020, 26 (17), 3877-3883.

(62) Ragon, F.; Chevreau, H.; Devic, T.; Serre, C.; Horcajada, P. Impact of the Nature of the Organic Spacer on the Crystallization Kinetics of UiO-66(Zr)-Type MOFs. Chem. - Eur. J. 2015, 21 (19), $7135-7143$.

(63) Shearan, S. J. I.; Jacobsen, J.; Costantino, F.; D’Amato, R.; Novikov, D.; Stock, N.; Andreoli, E.; Taddei, M. In Situ X-Ray Diffraction Investigation of the Crystallisation of Perfluorinated CeIVBased Metal-Organic Frameworks with UiO-66 and MIL-140 Architectures. Chem. - Eur. J. 2021, 27 (21), 6579-6592.

(64) Puchberger, M.; Kogler, F. R.; Jupa, M.; Gross, S.; Fric, H.; Kickelbick, G.; Schubert, U. Can the Clusters $\mathrm{Zr}_{6} \mathrm{O}_{4}(\mathrm{OH})_{4}(\mathrm{OOCR})_{12}$ and $\left[\mathrm{Zr}_{6} \mathrm{O}_{4}(\mathrm{OH})_{4}(\mathrm{OOCR})_{12}\right]_{2}$ Be Converted into Each Other? Eur. J. Inorg. Chem. 2006, 2006 (16), 3283-3293.

(65) Åberg, M.; Glaser, J. ${ }^{17} \mathrm{O}$ and ${ }^{1} \mathrm{H}$ NMR Study of the Tetranuclear Hydroxo Zirconium Complex in Aqueous Solution. Inorg. Chim. Acta 1993, 206 (1), 53-61.

(66) Büttgenbach, S.; Dicke, R.; Gebauer, H. Hyperfine Structure of the $5 \mathrm{~d}^{2} 6 \mathrm{~s}^{2}{ }^{3} \mathrm{~F}_{3,4}$ Metastable Atomic Levels of ${ }^{179} \mathrm{Hf}$ and the Nuclear 
Quadrupole Moments of ${ }^{177} \mathrm{Hf}$ and ${ }^{179}$ Hf. Phys. Lett. A 1977, 62 (5), 307-309.

(67) Terban, M. W.; Banerjee, D.; Ghose, S.; Medasani, B.; Shukla, A.; Legg, B. A.; Zhou, Y.; Zhu, Z.; Sushko, M. L.; De Yoreo, J. J.; Liu, J.; Thallapally, P. K.; Billinge, S. J. L. Early Stage Structural Development of Prototypical Zeolitic Imidazolate Framework (ZIF) in Solution. Nanoscale 2018, 10 (9), 4291-4300.

(68) Castillo-Blas, C.; Moreno, J. M.; Romero-Muñiz, I.; PlateroPrats, A. E. Applications of Pair Distribution Function Analyses to the Emerging Field of Non-Ideal Metal-Organic Framework Materials. Nanoscale 2020, 12 (29), 15577-15587.

(69) Anker, A. S.; Christiansen, T. L.; Weber, M.; Schmiele, M.; Brok, E.; Kjær, E. T. S.; Juhás, P.; Thomas, R.; Mehring, M.; Jensen, K. M. $\varnothing$. Structural Changes during the Growth of Atomically Precise Metal Oxido Nanoclusters from Combined Pair Distribution Function and Small-Angle X-Ray Scattering Analysis. Angew. Chem., Int. Ed. 2021, 60 (37), 20407-20416.

(70) Kelty, M. L.; Morris, W.; Gallagher, A. T.; Anderson, J. S.; Brown, K. A.; Mirkin, C. A.; Harris, T. D. High-Throughput Synthesis and Characterization of Nanocrystalline Porphyrinic Zirconium Metal-Organic Frameworks. Chem. Commun. 2016, 52 (50), 7854-7857.

(71) Bauer, S.; Serre, C.; Devic, T.; Horcajada, P.; Marrot, J.; Férey, G.; Stock, N. High-Throughput Assisted Rationalization of the Formation of Metal Organic Frameworks in the Iron(III) Aminoterephthalate Solvothermal System. Inorg. Chem. 2008, 47 (17), $7568-7576$.

(72) Basham, M.; Filik, J.; Wharmby, M. T.; Chang, P. C. Y.; El Kassaby, B.; Gerring, M.; Aishima, J.; Levik, K.; Pulford, B. C. A.; Sikharulidze, I.; Sneddon, D.; Webber, M.; Dhesi, S. S.; Maccherozzi, F.; Svensson, O.; Brockhauser, S.; Náray, G.; Ashton, A. W. Data Analysis WorkbeNch (DAWN). J. Synchrotron Radiat. 2015, 22 (3), 853-858.

(73) Juhás, P.; Davis, T.; Farrow, C. L.; Billinge, S. J. L. PDFgetX3: A Rapid and Highly Automatable Program for Processing Powder Diffraction Data into Total Scattering Pair Distribution Functions. J. Appl. Crystallogr. 2013, 46 (2), 560-566.

(74) Juhás, P.; Farrow, C. L.; Yang, X.; Knox, K. R.; Billinge, S. J. L. Complex Modeling: A Strategy and Software Program for Combining Multiple Information Sources to Solve Ill Posed Structure and Nanostructure Inverse Problems. Acta Crystallogr., 2015, A71 (6), $562-568$.

(75) Harris, C. R.; Millman, K. J.; van der Walt, S. J.; Gommers, R.; Virtanen, P.; Cournapeau, D.; Wieser, E.; Taylor, J.; Berg, S.; Smith, N. J.; Kern, R.; Picus, M.; Hoyer, S.; van Kerkwijk, M. H.; Brett, M.; Haldane, A.; del Río, J. F.; Wiebe, M.; Peterson, P.; Gérard-Marchant, P.; Sheppard, K.; Reddy, T.; Weckesser, W.; Abbasi, H.; Gohlke, C.; Oliphant, T. E. Array Programming with NumPy. Nature 2020, 585 (7825), 357-362.

(76) Virtanen, P.; Gommers, R.; Oliphant, T. E.; Haberland, M.; Reddy, T.; Cournapeau, D.; Burovski, E.; Peterson, P.; Weckesser, W.; Bright, J.; van der Walt, S. J.; Brett, M.; Wilson, J.; Millman, K. J.; Mayorov, N.; Nelson, A. R. J.; Jones, E.; Kern, R.; Larson, E.; Carey, C J; Polat, I.; Feng, Y.; Moore, E. W.; VanderPlas, J.; Laxalde, D.; Perktold, J.; Cimrman, R.; Henriksen, I.; Quintero, E. A.; Harris, C. R.; Archibald, A. M.; Ribeiro, A. H.; Pedregosa, F.; van Mulbregt, P.; Vijaykumar, A.; Bardelli, A. P.; Rothberg, A.; Hilboll, A.; Kloeckner, A.; Scopatz, A.; Lee, A.; Rokem, A.; Woods, C. N.; Fulton, C.; Masson, C.; Haggstrom, C.; Fitzgerald, C.; Nicholson, D. A.; Hagen, D. R.; Pasechnik, D. V.; Olivetti, E.; Martin, E.; Wieser, E.; Silva, F.; Lenders, F.; Wilhelm, F.; Young, G.; Price, G. A.; Ingold, G.-L.; Allen, G. E.; Lee, G. R.; Audren, H.; Probst, I.; Dietrich, J. P.; Silterra, J.; Webber, J. T; Slavic, J.; Nothman, J.; Buchner, J.; Kulick, J.; Schonberger, J. L.; de Miranda Cardoso, J. V.; Reimer, J.; Harrington, J.; Rodriguez, J. L. C.; Nunez-Iglesias, J.; Kuczynski, J.; Tritz, K.; Thoma, M.; Newville, M.; Kummerer, M.; Bolingbroke, M.; Tartre, M.; Pak, M.; Smith, N. J.; Nowaczyk, N.; Shebanov, N.; Pavlyk, O.; Brodtkorb, P. A.; Lee, P.; McGibbon, R. T.; Feldbauer, R.; Lewis, S.; Tygier, S.; Sievert, S.; Vigna, S.; Peterson, S.; More, S.; Pudlik, T.;
Oshima, T.; Pingel, T. J.; Robitaille, T. P.; Spura, T.; Jones, T. R.; Cera, T.; Leslie, T.; Zito, T.; Krauss, T.; Upadhyay, U.; Halchenko, Y. O.; Vazquez-Baeza, Y. SciPy 1.0: Fundamental Algorithms for Scientific Computing in Python. Nat. Methods 2020, 17 (3), 261272.

(77) Keen, D. A. A Comparison of Various Commonly Used Correlation Functions for Describing Total Scattering. J. Appl. Crystallogr. 2001, 34 (2), 172-177.

(78) Koschnick, C.; Stäglich, R.; Scholz, T.; Terban, M. W.; von Mankowski, A.; Savasci, G.; Binder, F.; Schökel, A.; Etter, M.; Nuss, J.; Siegel, R.; Germann, L. S.; Ochsenfeld, C.; Dinnebier, R. E.; Senker, J.; Lotsch, B. V. Understanding Disorder and Linker Deficiency in Porphyrinic Zirconium-Based Metal-Organic Frameworks by Resolving the $\mathrm{Zr}_{8} \mathrm{O}_{6}$ Cluster Conundrum in PCN-221. Nat. Commun. 2021, 12 (1), 3099.

(79) Momma, K.; Izumi, F. VESTA 3 for Three-Dimensional Visualization of Crystal, Volumetric and Morphology Data. J. Appl. Crystallogr. 2011, 44, 1272-1276.

(80) Daigle, M.; Bi, W.; Légaré, M. A.; Morin, J. F.; Fontaine, F. G. Synthesis of Carboxylate $\mathrm{Cp} * \mathrm{Zr}(\mathrm{IV})$ Species: Toward the Formation of Novel Metallocavitands. Inorg. Chem. 2015, 54 (11), 5547-5555. (81) Kalaji, A.; Soderholm, L. Aqueous Hafnium Sulfate Chemistry: Structures of Crystalline Precipitates. Inorg. Chem. 2014, 53 (20), $11252-11260$.

(82) Fitzgerald, M.; Pappas, I.; Zheng, C.; Xie, Z. L.; Huang, X. Y.; Tao, S.; Pan, L. First Hexanuclear Zirconium Macrocycle Sustained in a Chair-like Conformation by Glycolic Acids. J. Chem. Soc. Dalt. Trans. 2009, No. 32, 6289-6291.

(83) Mukherjee, A.; Sen, T. K.; Baskaran, S.; Sivasankar, C.; Mandal, S. K. Slow Hydrolysis of an Organozirconium Complex: The First Polyoxometallic Heptanuclear Zirconium Oxide. J. Organomet. Chem. 2015, 775, 76-79.

(84) Bai, G.; Ma, Q.; Roesky, H. W.; Vidovic, D.; Herbst-Irmer, R. New Synthetic Route for Organic Polyoxometallic Clusters: Synthetic and Structural Investigations on the First Dumb-Bell Shaped Polyoxozirconium Hydroxide with the $\left[\mathrm{Zr}_{9}\left(\mu_{5}-\mathrm{O}\right)_{2}\left(\mu_{3}-\mathrm{O}\right)_{4}(\mu\right.$ $\left.\mathrm{O})_{4}(\mu-\mathrm{OH})_{8}\right]$ Core Structure. Chem. Commun. 2003, 3 (7), 898-899.

(85) Kalaji, A.; Soderholm, L. A Novel Nonanuclear Hafnium Oxide-Hydroxide-Sulphate Cluster Crystallised from Aqueous Solution. Chem. Commun. 2014, 50 (8), 997-999.

(86) Kickelbick, G.; Wiede, P.; Schubert, U. Variations in Capping the $\mathrm{Zr}_{6} \mathrm{O}_{4}(\mathrm{OH})_{4}$ Cluster Core: X-Ray Structure Analyses of $\left[\mathrm{Zr}_{6}(\mathrm{OH})_{4} \mathrm{O}_{4}\left(\mathrm{OOC}-\mathrm{CH}=\mathrm{CH}_{2}\right)_{10}\right]_{2}\left(\mu \text {-OOC-CH }=\mathrm{CH}_{2}\right)_{4}$ and $\mathrm{Zr}_{6}(\mathrm{OH})_{4} \mathrm{O}_{4}(\mathrm{OOCR})_{12}(\mathrm{PrOH})\left(\mathrm{R}=\mathrm{Ph}, \mathrm{CMe}=\mathrm{CH}_{2}\right)$. Inorg. Chim. Acta 1999, 284 (1), 1-7.

(87) Kang, X. M.; Hu, H. S.; Wu, Z. L.; Wang, J. Q.; Cheng, P.; Li, J.; Zhao, B. An Ultrastable Matryoshka $\left[\mathrm{Hf}_{13}\right]$ Nanocluster as a Luminescent Sensor for Concentrated Alkali and Acid. Angew. Chem., Int. Ed. 2019, 58 (46), 16610-16616.

(88) Xu, T.; Hou, X.; Wang, Y.; Zhang, J.; Zhang, J.; Liu, B. A Gigantic Polyoxozirconate with Visible Photoactivity. Dalt. Trans. 2017, 46 (31), 10185-10188.

(89) Fidelli, A. M.; Karadeniz, B.; Howarth, A. J.; Huskić, I.; Germann, L. S.; Halasz, I.; Etter, M.; Moon, S.-Y.; Dinnebier, R. E.; Stilinović, V.; Farha, O. K.; Friščić, T.; Užarević, K. Green and Rapid Mechanosynthesis of High-Porosity NU- and UiO-Type MetalOrganic Frameworks. Chem. Commun. 2018, 54 (51), 6999-7002.

(90) Jacobsen, J.; Gosch, J.; Stock, N. Synthesis, Structure, and Characterization of Defect-Free $\left[\mathrm{Hf}_{6}\left(\mu_{3}-\mathrm{O}\right)_{4}\left(\mu_{3}-\mathrm{OH}\right)_{4}\left(\mathrm{C}_{4} \mathrm{H}_{2} \mathrm{O}_{4}\right)_{6}\right]$ (Hf-UiO-66-Fum). Z. Anorg. Allg. Chem. 2018, 644 (24), 1771-1776.

(91) Platero-Prats, A. E.; Mavrandonakis, A.; Gallington, L. C.; Liu, Y.; Hupp, J. T.; Farha, O. K.; Cramer, C. J.; Chapman, K. W. Structural Transitions of the Metal-Oxide Nodes within MetalOrganic Frameworks: On the Local Structures of NU-1000 and UiO66. J. Am. Chem. Soc. 2016, 138 (12), 4178-4185.

(92) Platero-Prats, A. E.; League, A. B.; Bernales, V.; Ye, J.; Gallington, L. C.; Vjunov, A.; Schweitzer, N. M.; Li, Z.; Zheng, J.; Mehdi, B. L.; Stevens, A. J.; Dohnalkova, A.; Balasubramanian, M.; Farha, O. K.; Hupp, J. T.; Browning, N. D.; Fulton, J. L.; Camaioni, D. 
M.; Lercher, J. A.; Truhlar, D. G.; Gagliardi, L.; Cramer, C. J.; Chapman, K. W. Bridging Zirconia Nodes within a Metal-Organic Framework via Catalytic Ni-Hydroxo Clusters to Form Heterobimetallic Nanowires. J. Am. Chem. Soc. 2017, 139 (30), 1041010418.

(93) Ling, S.; Slater, B. Dynamic Acidity in Defective UiO-66. Chem. Sci. 2016, 7 (7), 4706-4712.

(94) Katz, M. J.; Brown, Z. J.; Colón, Y. J.; Siu, P. W.; Scheidt, K. a; Snurr, R. Q.; Hupp, J. T.; Farha, O. K. A Facile Synthesis of UiO-66, UiO-67 and Their Derivatives. Chem. Commun. 2013, 49 (82), 9449.

(95) Øien-Ødegaard, S.; Bouchevreau, B.; Hylland, K.; Wu, L.; Blom, R.; Grande, C.; Olsbye, U.; Tilset, M.; Lillerud, K. P. UiO-67Type Metal-Organic Frameworks with Enhanced Water Stability and Methane Adsorption Capacity. Inorg. Chem. 2016, 55 (5), 19861991.

(96) Schaate, A.; Roy, P.; Godt, A.; Lippke, J.; Waltz, F.; Wiebcke, M.; Behrens, P. Modulated Synthesis of Zr-Based Metal-Organic Frameworks: From Nano to Single Crystals. Chem. - Eur. J. 2011, 17 (24), 6643-6651.

(97) Bon, V.; Senkovska, I.; Weiss, M. S.; Kaskel, S. Tailoring of Network Dimensionality and Porosity Adjustment in Zr- and HfBased MOFs. CrystEngComm 2013, 15 (45), 9572-9577.

(98) Gutov, O. V.; Hevia, M. G.; Escudero-Adán, E. C.; Shafir, A. Metal-Organic Framework (MOF) Defects under Control: Insights into the Missing Linker Sites and Their Implication in the Reactivity of Zirconium-Based Frameworks. Inorg. Chem. 2015, 54 (17), 83968400 . 